Research Article

\title{
Focus marking in Dutch by heritage speakers of Turkish and Dutch L1 speakers
}

\author{
Remy van Rijswijk ${ }^{a, *}$, Antje Muntendam ${ }^{a, b}$, Ton Dijkstra ${ }^{a, c}$ \\ ${ }^{a}$ Centre for Language Studies, Radboud University, PO Box 9103, 6500 HD Nijmegen, The Netherlands \\ ${ }^{\mathrm{b}}$ Florida State University, PO Box 3061540, Tallahassee, FL 32306-1540, United States \\ ' Donders Centre for Cognition, Radboud University, PO Box 9010//066, 6500 GL Nijmegen, The Netherlands
}

\section{A R T I C LE INFO}

\section{Article history:}

Received 28 January 2015

Received in revised form

2 January 2017

Accepted 5 January 2017

Available online 23 January 2017

\section{Keywords:}

Prosody

Focus marking

Semi-spontaneous speech

Turkish-Dutch bilingualism

Heritage speakers

Cross-linguistic influence

Language dominance

\begin{abstract}
A B S T R A C T
Studies on heritage speakers generally reveal effects from the dominant $L 2$ on the weaker $L 1$, but it is less clear whether cross-linguistic transfer also occurs in the other direction: from the L1 to the dominant L2. This study explores whether the Dutch prosody of heritage speakers of Turkish in the Netherlands differs from that of L1 speakers of Dutch who do not speak Turkish, and whether observed differences could be attributed to an effect of Turkish. The experiment elicited semi-spontaneous sentences in broad and contrastive focus. The analysis included fo movements, peak alignment, and duration. Although both participant groups used prosody to mark focus (e.g., time-compressed fo movements for contrastive focus), there were also differences between the groups. For instance, while the L1 speakers of Dutch showed declination, the bilinguals remained at the same pitch level throughout the sentence. Ipek (2015) and Kamalı (2011) also noted a limited pitch range in the prenuclear area in Turkish. We argue that the prosodic differences could be due to an effect of Turkish on Dutch prosody, suggesting that the weaker L1 in Turkish heritage speakers may affect the dominant L2 in the prosodic domain.
\end{abstract}

(c) 2017 Elsevier Ltd. All rights reserved.

\section{Introduction}

Approximately five decades ago, Turkish immigrants brought their culture, language, and families to the Netherlands. Nowadays the Turkish community, which forms $2.4 \%$ of the total population of the Netherlands, is the largest minority group in the country (Statistics Netherlands, 2014). It is known for the high maintenance of Turkish (Doğruöz \& Backus, 2007, 2009; Extra, Yağmur, \& van der Avoird, 2004). Yet, many children of Turkish immigrants report Dutch, the language they usually start learning when they go to (pre-)school, to be their dominant language.

The children of immigrants are often referred to as secondgeneration heritage speakers (Benmamoun, Montrul, \& Polinsky, 2013). They are born in a bilingual environment and generally acquire the heritage language, which is not the society's majority language, as their first language (L1). The language of society is their second language (L2) and often becomes the dominant language, partly because it is the language of instruction at school (e.g., Daller, Treffers-Daller, \& Furman, 2011; Hohenstein, Eisenberg, \& Naigles, 2006). Heritage speakers are a special type of bilingual, because in

\footnotetext{
* Corresponding author.

E-mail address: r.vanrijswijk@let.ru.nl (R. van Rijswijk).
}

most other bilinguals the L1 is the dominant language. Examining the interaction between a weaker L1 and dominant L2 might reveal different insights than from bilinguals whose $L 1$ is the dominant language, thereby contributing to our understanding of the bilingual mind. One important issue in this respect concerns language dominance. Whereas cross-linguistic transfer often occurs from the dominant L1 to the weaker L2 in many bilinguals (e.g., Hartsuiker, Pickering, \& Veltkamp, 2004; McAllister, Flege, \& Piske, 2002; Selinker \& Gass, 1992), it is unclear whether this is also the case for heritage speakers. In fact, most research on heritage speakers has found effects of the dominant $L 2$ on the weaker $L 1$, and not the other way around, indicating an important role for language dominance (e.g., Hohenstein et al., 2006; Montrul \& Ionin, 2010, 2012).

The present study aims at determining whether the dominant $\mathrm{L} 2$ of heritage speakers is affected by the weaker $\mathrm{L} 1$. We compared the Dutch prosody of focus marking in secondgeneration heritage speakers of Turkish in the Netherlands to that in L1 speakers of Dutch and checked for a Turkish influence. Typological differences in the prosody of focus marking between Turkish and Dutch make these heritage speakers an interesting group for testing whether the dominant L2 is affected by the heritage language.

In the rest of this Introduction, we first focus on the characteristics of heritage speakers and general findings of 
previous studies (Section 1.1). After describing earlier bilingual studies on cross-linguistic transfer in the prosodic domain (Section 1.2), we discuss scenarios that explain $L 1$ prosodic transfer (Section 1.3). Next, we examine Dutch and Turkish prosody regarding word stress (Section 1.4) and focus marking (Section 1.5). Finally, these differences are summarized and linked to our research questions (Section 1.6).

\subsection{Heritage speakers}

Most research on heritage speakers has concentrated on the heritage language. These studies addressed the question of how the $L 1$ of heritage speakers differs from the $L 1$ variety that is spoken in the country of origin (e.g., Benmamoun et al., 2013; Montrul, 2008). Differences between the two varieties involve a wide range of linguistic features at different levels, such as morpho-syntax, the lexicon, and the syntax-discourse interface (e.g., Bolonyai, 2007; Montrul, 2004a; Polinsky, 2006). Regarding phonetics, the findings are somewhat divergent: McCarthy, Evans, and Mahon (2013) showed difficulties in the production of some phonetic categories in the heritage language, whereas Chang, Haynes, Yao, and Rhodes $(2008,2009)$ revealed that heritage speakers are relatively good at distinguishing phonetic categories in their L1.

The considerable differences between heritage languages and the L1 variety in the country of origin have led to a comparison between heritage speakers and adult learners (e.g., Montrul, 2008). In fact, studies have shown similarities between the two. For example, Montrul (2004b) showed similar incomplete grammars for the Spanish of heritage speakers and L2 learners of Spanish.

That heritage languages generally diverge from the variety in the country of origin and often pattern together with the L2 of adult learners indicates that acquisition of the heritage language in early childhood is not sufficient for native-like attainment in that language. A more important role is attributed to language input, as input in the heritage language often decreases when heritage speakers go to school (Montrul, 2008), whereas input in the L2 increases. Given the importance of input for competence in that specific language, the question arises to what extent the dominant L2 of heritage speakers differs from the variety that is spoken by non-heritage $\mathrm{L} 1$ speakers in the host country. If input plays an equally important role in $L 2$ acquisition as in L1 acquisition, we would expect more native-like performance in the L2. In fact, several studies revealed crosslinguistic effects of the dominant language on the weaker language, and not in the opposite direction (e.g., Argyri \& Sorace, 2007; Daller et al., 2011; Hohenstein et al., 2006; McCarthy et al., 2013; Montrul \& Ionin, 2010; Serratrice, 2007). However, some studies suggest effects of the weaker L1 on the dominant L2 in heritage speakers (e.g., Blom \& Baayen, 2013; Montrul, 2006; Queen, 2012; Van Meel, Hinskens, \& Van Hout, 2013, 2014). Clearly, more research is necessary to advance our understanding of bidirectional effects of the heritage speakers' languages and the role of language dominance. Our study contributes to this issue.

\subsection{Cross-linguistic transfer in the prosodic domain}

Research has shown cross-linguistic influences in the prosodic domain for language combinations like German-English, Dutch-Greek, and Catalan-Spanish (e.g., Atterer \& Ladd, 2004; Mennen, 2004; Simonet, 2008). These studies comprise a variety of prosodic features, such as peak alignment, the transfer of pitch accents, and duration, and differ in type of bilingual (L2 learners, early simultaneous bilinguals, and or heritage speakers). Several studies found differences in peak alignment between bilinguals and a control group (e.g., Atterer \& Ladd, 2004; Elordieta, 2003; Elordieta \& Calleja, 2005; Mennen, 2004). Peak alignment differences were also reported for Spanish monolinguals in Buenos Aires, where the prosodic change was attributed to contact with Italian, a former immigrant language (Colantoni \& Gurlekian, 2004). Moreover, compared to initial accents, these speakers lowered final accents in utterances more than speakers of other Spanish varieties, which might also reflect an Italian influence. Other studies reported cross-linguistic prosodic influence for different f0 features. Speakers with Mandarin Chinese or Korean as their L1 transferred f0 patterns to their L2 English (McGory, 1997), and French-American English bilinguals transferred pitch accents from English to French (Bullock, 2009). Simonet's (2008, 2011) studies on Majorcan Catalan-Spanish bilinguals revealed that Spanish-dominant speakers adopted features of a Catalan nuclear pitch accent in their Spanish. Interestingly, women used more Catalan-like intonation in their Spanish than men. Gender may thus be a relevant factor in studies on bilingual prosody. More generally, women have been found to take a leading role in studies on linguistic change (Labov, 2001).

Other prosodic features than pitch can also be affected. For instance, Gut (2005) reported an influence from tone languages spoken in Nigeria on Nigerian English, regarding speech rhythm, syllable structure, and syllable length.

The effect of the speakers' weaker heritage language on their dominant L2 has received little attention, with some exceptions. Queen (2012) found that the Turkish and German intonation of heritage speakers of Turkish in Germany was different from Turkish and German intonation as described in the literature. She compared her bilingual data to those of German and Turkish control groups. The bilinguals and the Turkish control group used two phrase-final rising tones in German, which were not, or were to a lesser extent, used by the German control group. According to Queen, one of these rises, which was marked by a relatively steep slope, had its origin in Turkish, and expressed narrative salience. This tentatively points towards a prosodic transfer from the weaker heritage language to the L2. However, control group speakers were not matched to bilinguals for age, education, and region, and most speakers had some knowledge of the other language. As Queen notes, the lack of a systematic comparison between comparable Turkish-German bilinguals and L1 speakers of German without any knowledge of Turkish prevents us from drawing firm conclusions. The present study examines the Dutch prosody of heritage speakers of Turkish in the Netherlands and compares it to the prosody of L1 speakers of Dutch who are similar regarding age, education, and region. We will now briefly discuss how prosodic transfer of the L 1 may arise in these heritage speakers. 


\subsection{Explanations for $L 1$ prosodic transfer}

At least three different scenarios are possible to explain L1 transfer: direct transfer, early childhood transfer, and indirect transfer.

\subsubsection{Direct transfer}

Direct transfer occurs through co-activation of the $\mathrm{L} 1$ during language production and comprehension (e.g., Costa, 2005; Dijkstra, 2005). Many studies have shown that both languages are activated in bilinguals, even in language-specific contexts (e.g., Amengual, 2012; Blumenfeld \& Marian, 2007; Costa, 2005; Dijkstra, Grainger, \& Van Heuven, 1999; Hartsuiker et al., 2004; Hatzidaki, Branigan, \& Pickering, 2011). In addition, for similar heritage speakers as in the present study, Muntendam, Van Rijswijk, and Dijkstra (2017) demonstrated that Turkish is also activated during auditory processing in Dutch. Thus, the direct transfer scenario proposes that prosodic features of the $L 1$ are activated while speaking in the $L 2$, leading to transfer of these features to the L2.

\subsubsection{Early childhood transfer}

Early bilinguals are most likely to transfer $\mathrm{L} 1$ features to $\mathrm{L} 2$ during early childhood, especially when the L1 is the stronger language. After this period, they are better able at separating the two systems (e.g., Hernandez, Li, \& MacWhinney, 2005), and make more efficient use of inhibition to suppress the nonrequired, co-activated language (e.g., Abutalebi \& Green, 2007). Second-generation Turkish heritage children in the Netherlands were dominant in Turkish at age 5 and 6, which makes L1 transfer in this stage more probable (Verhoeven, 2007). This may hold especially for prosody, which is one of the first aspects of language that is acquired. Six- and 9-months-old infants can already perceive prosodic phrase boundaries in their language (e.g., Gerken, Jusczyk, \& Mandel, 1994; Gout, Christophe, \& Morgan, 2004; Soderstrom, Seidl, Nelson, \& Jusczyk, 2003). Christophe, Nespor, Guasti, and Van Ooyen (2003) showed that French infants between 2 to 3 months old made use of prosodic cues to correctly distinguish French from Turkish sentences. In this scenario, the bilinguals transferred L1 prosodic features during L2 acquisition, creating a new variety of Dutch with distinct prosodic characteristics.

\subsubsection{Indirect transfer}

Early childhood transfer is also possible for the first generation of Turkish immigrants. Turkish is their dominant language, which makes L1 transfer of prosodic features (through coactivation, according to the scenario of direct transfer) to the L2 Dutch prosodic system more likely. This may also lead to a new variety of Dutch. Subsequently, the second generation acquired these prosodic features indirectly through their parents and peers. This scenario has also been described as accommodation (Romera \& Elordieta, 2013) or incipient changes of the input (Benmamoun et al., 2013).

\subsection{Word stress in Dutch and Turkish}

Dutch and Turkish differ regarding word stress. While stress position is free in Dutch, with a tendency for stress (indicated by capital letters in the examples) on the first syllable
(Van Donselaar, Koster, \& Cutler, 2005; e.g., Appel, 'apple'), word stress in Turkish is regular and normally falls on the final syllable (Inkelas \& Orgun, 2003; e.g., elMA, 'apple').

A distinction is made between stress-accent languages, in which lengthening of the stressed syllable is the most important cue for word stress, and pitch-accent languages, in which f0 movements are a more important cue for word stress than duration and intensity (Beckman, 1986). Dutch is a stressaccent language (Nooteboom, 1972; Sluijter \& van Heuven, 1995; Sluijter \& Van Heuven, 1996; Van Heuven, 2014), but it is unclear how Turkish should be categorized. Although several studies suggest that Turkish is a stress-accent language (e.g., Inkelas, 1999; Ipek, 2015), Levi (2005) found noticeable differences between stressed and non-stressed syllables for f0 peaks in Turkish, with higher fo peaks for stressed syllables, as in pitch-accent languages. However, Levi's analysis is limited to words that received the final accent in the phrase (Ipek, 2015; Ladd, 2008). It is therefore not clear whether f0 movements are due to word stress or to this phrasal accent. These two factors can be easily confounded (Sluijter \& Van Heuven, 1996). Thus, whether Turkish should be described as a stress-accent or pitch-accent language is unresolved.

\subsection{Focus marking}

Most bilingual studies in Section 1.2 concern the relationship between information structure and prosody, or more specifically, focus. Roughly speaking, focus is the new information in a sentence (Jackendoff, 1972). Different types of focus have been discerned: broad and narrow focus, and neutral and contrastive focus (Gussenhoven, 2007). Broad focus involves the whole sentence and can be evoked by the question in (1a).

(1) a. What is happening?

b. [Emma is eating peanuts $]_{\mathrm{F}}$.

Focus on one constituent in the sentence is narrow focus (2b):

(2) a. What is Emma eating?

b. Emma is eating [peanuts] $]_{F}$.

The focus in $(2 b)$ is neutral, non-contrastive focus. Contrastive or corrective focus, on the other hand, occurs when information in the question is rejected and changed into a new value (3b) (Gussenhoven, 2005, 2007):

(3) a. Is Emma eating grapes?

b. No, Emma is eating [peanuts $]_{F}$.

Note that 'Emma' in (2b) and (3b) is topic, information that was introduced previously and is thus not in focus. Topic is the entity in the sentence about which information is given (Chen, 2007).

Languages have different strategies to encode focus, such as syntactic or prosodic strategies. Regarding syntax, information can be highlighted by a change in word order. That is, the focused element can be moved to a marked position in the sentence, e.g., fronting. Prosodically, a constituent can be made more prominent through changes in suprasegmental features, such as pitch and duration. Because of these cross-linguistic 
differences, prosodic focus marking is a recurring topic in bilingual studies, which have often revealed cross-linguistic effects (e.g., Colantoni \& Gurlekian, 2004; Elordieta, 2003; Simonet, 2011). There are also differences in focus marking between Dutch and Turkish. As discussed below, Dutch mostly uses prosody to mark focus (e.g., Bouma, 2008; Chen, 2009; Hanssen, Peters, \& Gussenhoven, 2008), whereas Turkish uses both word order and prosody (e.g., İșsever, 2003; Özge \& Bozsahin, 2010).

\subsubsection{Focus in Dutch}

Dutch word order is relatively fixed, and main clauses that do not start with an adverb have SVO order (Bouma, 2008). Focus is mainly marked in prosody. Several studies have examined prosodic features of focus marking in Dutch. Hanssen et al. (2008) observed phonetic differences in duration and fO between broad, neutral, and contrastive focus for the nuclear accent (i.e., the final accent in the sentence ${ }^{1}$ ), which was described as a fall $(\mathrm{H} * \mathrm{~L})$. In particular, they found a longer duration for the syllable carrying the nuclear accent in contrastive and neutral focus than in broad focus. Regarding f0, a higher peak was found for broad and contrastive focus than for neutral focus. Contrastive and neutral focus were marked by a steeper fall than broad focus and by postfocal pitch reduction. Peak alignment and alignment of the minimum after the peak occurred earlier in contrastive and neutral focus than in broad focus. In conclusion, Hanssen et al. (2008) showed a timecompressed pitch movement for the nuclear accent in contrastive and neutral focus as compared to broad focus.

Chen $(2007,2009)$ compared the phonetic realization of topic and neutral focus. She examined sentence-initial and sentencefinal accents. While in sentence-final position topic was frequently deaccented, in sentence-initial position it was often accompanied by $\mathrm{H} * \mathrm{~L}$. The nuclear accent was frequently downstepped. Phonetically, words in neutral focus were marked by a larger f0 excursion, earlier peak alignment, and a lower and earlier f0 minimum after the peak than topics. Moreover, words in neutral focus were longer than topics.

As yet, no studies seem to have explored the phonetic realization of sentence-initial constituents in broad and contrastive focus in declaratives. The only studies that considered prenuclear accents in broad and contrastive focus in Dutch are Ladd, Mennen, and Schepman (2000) and Krahmer and Swerts (2001). Ladd et al. (2000) examined the phonetic factors that affect the alignment of prenuclear rising accents on adjectives in broad focus sentences, such as rennende, 'running' in (4).

(4) Wij konden de rennende atleten met geen mogelijkheid bijhouden.

'There was no way we could keep up with the running athletes.'

Their study indicates that prenuclear accents in broad focus are characterized by a rise within the stressed syllable, with the end of the rise in the vowel in the case of long vowels and in the following consonant in the case of short vowels.

\footnotetext{
Although the nuclear accent is the final accent in the sentence, it does not necessarily occur on the final word in the sentence: It can be followed by deaccented words. For example, in Hanssen et al. (2008) the nuclear accent was followed by two verb forms.
}

Krahmer and Swerts (2001) analyzed contrastive focus in noun phrases with an adjective followed by a noun. They concluded that contrastive accents are similar to nuclear accents. That is, although the adjective occurred before the noun, the nuclear accent was located on the adjective when this word was in contrastive focus, because the following noun was deaccented (Krahmer \& Swerts, 2001).

In sum, Dutch uses differences in f0 movements and duration to mark focus (Chen, 2007, 2009; Hanssen et al., 2008). Sentence-initial constituents in whole sentences in broad and contrastive focus have not been examined prosodically. Ladd et al. (2000) described prenuclear accents that are not in sentence-initial position in broad focus that are accompanied by a rising accent, and Krahmer and Swerts (2001) showed that deaccenting usually follows after contrastive focus in noun phrases. The present study is the first to examine sentenceinitial subjects and sentence-final objects in broad and contrastive focus in complete sentences. It does not only compare the Dutch prosody of L1 speakers of Dutch to that of heritage speakers of Turkish, but also informs about aspects of Dutch prosody that have not been investigated before.

\subsubsection{Focus in Turkish}

Turkish uses both word order and prosody to convey focus (Güneș, 2013; İșsever, 2003; Kamalı, 2011; Özge \& Bozsahin, 2010). The canonical word order in Turkish is SOV, but other orders are possible depending on the information structure of the sentence. Preverbal constituents can express focused information and are accented. Postverbal elements cannot be in focus and are obligatorily deaccented. In (5), the subject is placed after the verb and deaccented, indicating that the subject is not in focus (Vallduví \& Engdahl, 1996).

$\begin{array}{ll}\text { (5) }[\text { Öldü] }]_{F} & \text { bașkan. (VS) } \\ \text { die-PST-3s } & \text { president } \\ \text { 'The president died.' } & \end{array}$

Another example is (6) (İsssever, 2003: 1047). While in (6a) ağaçtan, tree-ABL, 'from the tree', appears preverbally and is accented and focused, in (6b) it occurs postverbally and is deaccented and unfocused. In (6b), the focus is on bir çocuk, 'a child'.

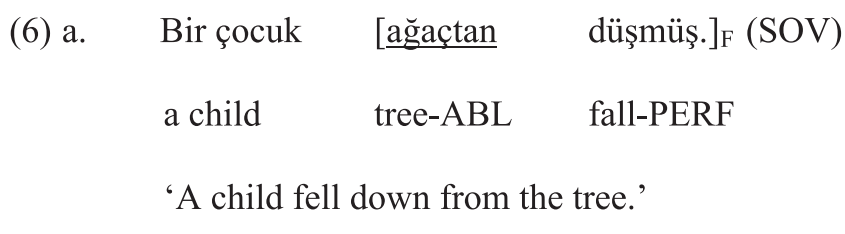

b. $\quad[\text { Bir çocuk }]_{F}$ düşmüş ağaçtan. (SVO)
a child
fall-PERF
tree-ABL

'A child fell down from the tree.'

The scarce descriptions of Turkish intonation concern broad and neutral focus (Ipek, 2011, 2015; Ipek \& Jun, 2013; Kamalı, 2011). Kamalı (2011) and Ipek (2015) propose different phonological models of Turkish intonation. Whereas Kamalı (2011) 
assumes that Turkish is a pitch-accent language (following Levi (2005)), Ipek (2015) argues that Turkish is a stress-accent language.

Kamalı (2011) analyzed the intonation of broad focus sentences in Turkish, with a nominative argument, accusative argument, dative argument, and a verb (in this order). The dative argument carried the nuclear accent, and is referred to as 'nuclear word'. Kamalı investigated intonational differences between words with lexical (non-final) stress and words with regular (final) stress. Only words with lexical stress carried a $\mathrm{H} * \mathrm{~L}$ pitch accent. Words with regular stress were accentless. Furthermore, nuclear words were marked by a terracing pattern L-: No pitch accent was observed on these words, but only a low tone that continued at the same level, until an fo drop into the following verb. Kamalı attributes this L- to the presence of the verb after the nuclear word. That is, the even lower fo level on the verb triggers the L- on the nuclear word. Kamalı's explanation of the L- on nuclear words is based on separate prosodic phrasing of the prenuclear and nuclear domain. This distinction in Turkish between the prenuclear area on the one hand, and nuclear and postnuclear areas on the other, has also been made by other researchers (e.g., Güneș, 2013; Kabak \& Vogel, 2001). In further support of this distinction, Kamalı observed that the pitch range of Turkish sentences was limited and that there did not seem to be declination or downstep in the prenuclear area. A following peak could even be higher than its predecessor.

Ipek's (2015) model for broad focus declaratives differs in some aspects from Kamalı's model. First, unlike Kamalı, Ipek considers Turkish to be a stress-accent language. All words carry pitch accents, regardless of stress position. If these pitch accents occur on a prenuclear word at the edge of a prosodic phrase, they are also boundary tones $(\mathrm{H} * \mathrm{H}-)$. Second, Ipek proposes that the high boundary tone $(\mathrm{H}-)$ on the word preceding the nuclear word has an important function marking sentence prominence. Whereas in other languages the nuclear word is the most prominent in the sentence and marks sentence prominence, in Turkish this is not the case, because (post-) nuclear words have a rather compressed pitch range. This explanation is further supported by a prominence judgement task in Ipek (2015), in which listeners showed more difficulties determining the most prominent word when the boundary tone was removed from the acoustic signal than when the nuclear pitch accent was deleted.

To our knowledge, there are no phonetic studies on contrastive focus in Turkish. Ipek (2011) examined the acoustic correlates of non-contrastive narrow focus in different positions (initial, medial, and final) in SOV sentences. Focused words had a longer duration and higher intensity than non-focused words. Ipek did not find a pitch range expansion, but the f0 peaks preceding the word in focus were higher, similar to the nuclear words in broad focus in Ipek (2015) and Kamalı (2011). Sentence-initial focus was followed by postfocal pitch reduction, but no lowered pitch for pre- or postfocus was observed for the other two positions. Thus, Ipek (2011) suggests that focus in Turkish may be marked by longer durations and higher intensity rather than by f0 movements on the word in focus.

To summarize, Turkish uses both word order and prosody to mark focus. Although Kamalı (2011) and Ipek (2015) differ regarding their interpretation of word stress in Turkish, both argue that there is a clear distinction between the prenuclear and nuclear area in Turkish broad focus sentences, with a high prominence-lending boundary tone at the rightmost edge of the prenuclear area and a compressed pitch range in the (post-) nuclear domain.

\subsection{Summary and research questions}

As discussed above, focus in Dutch is mainly indicated by prosody, while Turkish also makes use of word order, and has more restrictions with respect to prosody. Specifically, in Turkish there is a distinction between the prenuclear prosodic phrase, which is marked with a high boundary tone at the right edge, and the (post-)nuclear domain, which is characterized by a compressed pitch range and declination (lpek, 2015; Kamalı, 2011). Focused, accented elements are not allowed in the postnuclear area (İșsever, 2003; Özge \& Bozsahin, 2010). In Dutch, no such distinction between the prenuclear and (post-) nuclear area exists in SVO main clauses (Bouma, 2008): Each word can be accented in each position in the sentence. Dutch uses differences in pitch for the prosodic marking of topic and (contrastive) focus (Chen, 2007, 2009; Hanssen et al., 2008). For Turkish, it is less clear how contrastive focus is marked, but Ipek (2011) shows that there may be a larger contribution of other suprasegmental features in Turkish, such as duration. In all, the studies mentioned above suggest prosodic differences between the two languages, involving the interplay of prosodic features, such as pitch and duration.

This study explores potential differences between heritage speakers of Turkish and a control group of L1 speakers of Dutch regarding prosodic focus marking in Dutch. The study contributes to the field of bilingualism, exploring to what extent a dominant L2 may be affected by the weaker L1. It also offers a more fine-tuned picture of Dutch prosody by examining the prosody of sentence-initial subjects in broad and contrastive focus in SVO sentences. Another novel aspect of the study concerns the semi-spontaneous character of the data. We do not know any studies that elicited Turkish or Dutch semispontaneous complete sentences in broad and contrastive focus (see Chen $(2007,2009,2011)$, for neutral focus in Dutch complete sentences; Krahmer \& Swerts, 2001, for broad and contrastive focus in Dutch noun phrases; and Turco, Braun, \& Dimroth (2014), for polarity contrasts in Dutch). Given that the prosody of spontaneous speech may differ considerably from read speech (Blaauw, 1994; Face, 2003), it is important to study semi-spontaneous speech as a form of speech that approaches natural speech more than read speech.

The research questions addressed in this paper are:

(1) How do Dutch L1 speakers and Turkish heritage speakers mark focus in Dutch?

More specifically, how do L1 speakers of Dutch and heritage speakers of Turkish phonetically mark sentence-initial and sentence-final constituents in broad and contrastive focus in semi-spontaneous speech?

(2a) Are there differences in focus marking between the bilinguals and L1 speakers? 


\section{(2a) Can such differences be attributed to Turkish?}

To answer these questions, a production task was developed to elicit semi-spontaneous declaratives in three focus conditions: broad focus, contrastive focus on the subject (in sentence-initial position), and contrastive focus on the object (in sentence-final position), following Muntendam (2009, 2013, 2015).

\section{Method}

\subsection{Participants}

xThe participants were eight Turkish-Dutch bilinguals and a control group of eight L1 speakers of Dutch who did not speak Turkish. Half of each group was female. Given that there are prosodic differences across regional varieties of Dutch (Peters, Hanssen, \& Gussenhoven, 2014), only participants who were born in Nijmegen and were living there at the time of recording were selected. The two groups of participants were matched for age (mean for the Turkish-Dutch bilinguals: 31.5 years, ranging from 26 to 37 years; mean for the Dutch L1 speakers: 31 years, ranging from 25 to 37 years). The groups were also comparable regarding education: Five Dutch L1 speakers and four TurkishDutch participants finished intermediate vocational education, three Dutch L1 speakers and two Turkish-Dutch bilinguals finished higher professional education, and two Turkish-Dutch bilinguals only finished high school.

Prior to the experiment, all participants completed a sociolinguistic background questionnaire about language acquisition and language use, and language proficiency ratings. All TurkishDutch bilinguals had Turkish as their L1, and learned Dutch from a young age (generally between two and four years). The bilinguals' parents were born in Turkey.

After the experiment, the participants performed the Boston Naming Test (BNT) (Kaplan, Goodglass, Weintraub, Segal, \& Van Loon-Vervoorn, 2001) in Dutch and Turkish. This test was used, together with the self-rated language proficiency scores, to measure the participants' language proficiency. The results on the language proficiency ratings and BNT confirm that the language of society (Dutch) was the bilinguals' dominant language (see Appendix A for means, standard deviations, and analysis), which is typical for heritage speakers.

\subsection{Stimulus materials}

The participants heard questions that they were requested to answer by describing pictures. Every picture occurred three times throughout the experiment, with different questions, leading to three focus types: broad focus (BROAD) (7), contrastive focus on the subject (CoNTR.S) (8), and contrastive focus on the object (CONTR.O) (9). There were no pre-scripted answers; the utterances in (7)-(9) are target answers.

(7) a. Wat gebeurt er? What is happening?'

b. De oma wast de ramen.

'The grandmother is washing the windows.'

(8) a. Wast de heks de ramen? 'Is the witch washing the windows?'

b. Nee, de oma wast de ramen.

'No, the grandmother is washing the windows.'
(9) a. Wast de oma de borden?

'Is the grandmother washing the plates?

b. Nee, de oma wast de ramen.

'No, the grandmother is washing the windows.'

There were 45 target utterances. Beside these $45 * 3$ experimental items, there were 64 distractor question-answer pairs, which elicited neutral narrow focus and contained different lexical items. This led to a total of 199 question-answer pairs.

The target constituents in the target utterances were definite noun phrases. Voiceless stops in the target words (subjects and objects) were avoided to facilitate the analysis of pitch and peak alignment. Only $9 \%$ of the words had a voiceless stop in its onset. The target words consisted of two $(78.9 \%)$ or three syllables $(21.1 \%)$ and carried stress on the first syllable. A total of $83.3 \%$ of the stressed syllables were open syllables, whereas $16.7 \%$ were closed. The vowel in the stressed syllable was short in $44.4 \%$ and long in $55.6 \%$ of the cases. Because the number of syllables, syllable type, and vowel length may affect the alignment of pitch movements (e.g., Ladd et al., 2000), these factors were considered in the analysis (see Section 2.5). The objects in the target utterances were direct objects, indirect objects, or prepositional objects. Because the grammatical function of the object affected the length of the utterance, it was taken into account in the statistical analysis (Section 2.5).

\subsection{Procedure}

The questions were recorded by a 26 -year old male native speaker of Dutch from the eastern part of the Netherlands. Recordings were made in a soundproof studio at the Radboud University. The task was presented using Presentation $₫$ software (Version 16.3, www.neurobs.com).

In the experiment, an animated figure asked the recorded questions in a pseudo-random order. None of the target pictures and target words in one trial was repeated in the subsequent trial. The stimuli were presented in a different order for each participant.

The data were recorded with Sony MiniDisc Recorder MZ$\mathrm{NH} 700$ and Sony ECM-MS907 microphone. Prior to the task, the participants received instructions from the animated figure and were requested to respond in complete sentences. In the instructions, the animated figure gave examples of questionanswer pairs to illustrate how the participants should respond. The instructions were followed by a practice part with 14 question-answer pairs.

During the task, pictures appeared on the computer screen, for instance a drawing of a grandmother washing the windows. To elicit contrastive focus, two additional pictures appeared below the target picture, one of the target referent and one of an alternative (i.e., one of a grandmother and one of a witch) (see Appendix B). The experiment took approximately 30 minutes.

\subsection{Data selection and analysis}

The semi-spontaneous character of the data resulted in variability among the utterances. Because our aim was to analyze the speakers' prosody as systematically as possible, a subset of 24 target sentences $* 3$ focus conditions that were most fluent and comparable across the 16 speakers, was 
Table 1

Measurements from the target sentences in Praat.

\begin{tabular}{|c|c|}
\hline \multicolumn{2}{|l|}{ F0 movements } \\
\hline $\min 1$ & $\begin{array}{l}\text { fo minimum within the word before the peak } \\
\text { in ST }\end{array}$ \\
\hline peak & f0 maximum within the word in ST \\
\hline $\min 2$ & $\begin{array}{l}\text { fo minimum within the word after the peak in } \\
\text { ST }\end{array}$ \\
\hline \multicolumn{2}{|l|}{ Peak alignment } \\
\hline peak location & $\begin{array}{l}\text { location of the peak in ms relative to the end } \\
\text { of the stressed syllable }\end{array}$ \\
\hline \multicolumn{2}{|l|}{ Duration } \\
\hline $\begin{array}{l}\text { duration stressed syllable } \\
\text { total duration }\end{array}$ & $\begin{array}{l}\text { duration of the stressed syllable in } \mathrm{ms} \\
\text { duration of the word in } \mathrm{ms}\end{array}$ \\
\hline
\end{tabular}

selected for analysis. The following data were excluded: (1) utterances with a different word order, e.g., with objects in non-final position; (2) utterances with lexical items that did not have word stress on the first syllable or contained voiceless stops (e.g., papa, 'dad' for vader, 'father'); (3) sentences with a boundary tone after the subject; (4) sentences with pauses and/ or hesitations, and (5) repeated or corrected utterances.

The data were analyzed in Praat (Boersma \& Weenink, 2010). Syllable boundaries were determined by using both visual (the waveform and spectrogram) and auditory information. A script was used to automatically determine f0 minima and maxima. These were manually checked and corrected when necessary, that is, in the case of octave jumps, increased pitch on voiceless stops, or creaky voice.

Given the differences in f0 movements, peak alignment, and duration between broad and narrow focus found by Hanssen et al. (2008) and Chen (2009), we were interested in several variables of the target words (subjects and objects). Concerning fo movements, we examined the minimum before the peak within the word $(\min 1)$, the peak, the minimum after the peak within the word (min2), the rise from the first minimum to the peak, the fall from the peak to the second minimum, and the slopes of the rises and falls. All f0 values were converted to semitones (ST) with $100 \mathrm{~Hz}$ as a reference. Semitones reflect listeners' perception of changes in pitch more accurately than Hertz, and are used to make a fair comparison between male and female speakers' fo movements (Simpson, 2009). ${ }^{2}$ For peak alignment, we measured the location of the peak in $\mathrm{ms}$ relative to the end of the stressed syllable, yielding negative values for peak alignment within the stressed syllable, and positive values for peaks in the posttonic syllable. We also measured the duration of the stressed syllable and of the word (in ms). The durational difference between the stressed and posttonic syllable(s) was also measured. Moreover, given that prosodic prominence is dependent on its surroundings (Krahmer \& Swerts, 2001), we also measured the difference between the peaks on the subject and object (peak range). We expected positive values, with higher peaks on the subject than on the object, given the natural trend of declination in declaratives (Gussenhoven, 2005a). We further computed durational

\footnotetext{
${ }^{2}$ Physical f0 changes (as reflected in Hertz) do not correspond to what we perceive: The higher the pitch, the larger the physical fo difference needs to be to be perceived as a difference in f0. This leads to larger fo changes for women than what listeners perceive, and smaller fo changes for men than what listeners perceive. This non-linear perception of f0 changes is captured in the logarithmic measure of semitones (Simpson, 2009).
}

Table 2

Variables that were calculated from the measurements in Table 1.

\begin{tabular}{|c|c|}
\hline \multicolumn{2}{|l|}{ F0 movements } \\
\hline rise & peak - min1 in ST \\
\hline fall & peak $-\min 2$ in ST \\
\hline slope of the rise & $\begin{array}{l}\text { (rise)/(distance between peak and } \min 1 \text { in } \\
\mathrm{ms} \text { ) }\end{array}$ \\
\hline slope of the fall & $\begin{array}{l}(\text { fall }) /(\text { distance between peak and } \min 2 \text { in } \\
\mathrm{ms})\end{array}$ \\
\hline peak range & $\begin{array}{l}\text { peak subject - peak (direct/prepositional/ } \\
\text { indirect) object in the sentence, in ST }\end{array}$ \\
\hline \multicolumn{2}{|r|}{ 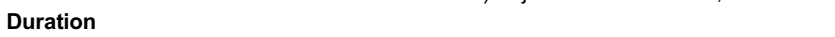 } \\
\hline relative duration & $\begin{array}{l}\text { duration stressed syllable/total duration in } \\
\mathrm{ms}\end{array}$ \\
\hline $\begin{array}{l}\text { difference stressed } \\
\text { syllable duration }\end{array}$ & $\begin{array}{l}\text { sduration subject - sduration object in the } \\
\text { sentence, in ms }\end{array}$ \\
\hline difference total duration & $\begin{array}{l}\text { total duration subject - total duration object } \\
\text { in the sentence, in } \mathrm{ms}\end{array}$ \\
\hline difference relative duration & $\begin{array}{l}\text { relative duration subject - relative duration } \\
\text { object in the sentence, in ms }\end{array}$ \\
\hline
\end{tabular}

differences between subject and object, concerning the stressed syllable, the total duration of the word, and the relative duration. We expected that the durational differences between subject and object would show negative values because of final lengthening in Dutch sentences (Hofhuis, Gussenhoven, \& Rietveld, 1995): The final word in the sentence is usually longer compared to preceding words. Table 1 summarizes the measurements that were taken in Praat, and Table 2 lists the acoustic variables that were calculated from the measurements.

\subsection{Statistical data analysis}

For all acoustic variables, we fitted mixed-effect models using the Imer function of the ImerTest package (Kuznetsova, Brockhoff, \& Bojesen Christensen, 2014) in R (R Core Team, 2014). The random factors were 'Subject' and 'Sentence'. The fixed factors were 'Group' (Turkish, Dutch) and 'Focus' (BROAD, CONTR.S, Contr.O). Furthermore, because Simonet (2011) revealed a leading role of women regarding prosodic transfer, we examined our data for gender differences. The fixed effects were only incorporated in the model if they led to a better fit, which was tested with the anova function in R. The effect of 'Gender' (Female, Male) is only discussed when the effect can be explained by other factors than the intrinsic differences in pitch between male and female speakers (i.e., in the case of interactions with Focus and Group). ${ }^{3}$ A Bonferroni correction was applied and therefore all effects are reported at a .0167 level of significance. Only significant differences are discussed.

\footnotetext{
${ }^{3}$ In a different analysis, in addition to 'Group', 'Focus', and 'Gender', we included the fixed factors 'Age', 'Education', 'Number of syllables', 'Vowel length', 'Syllable, 'Duration of the stressed syllable', 'Function', 'Dutch BNT score', and Self-rated language proficiency scores for Dutch. Word intrinsic variables might especially affect peak alignment and duration (e.g., Ladd et al., 2000). Characteristics of the participants could also affect speakers' prosody. Although the bilinguals were all dominant in Dutch, there might be individual differences in language input dependent on these variables, but adding or removing them did not affect our main results. To avoid issues of potential collinearity we focus on the simpler analysis in the main text.
} 


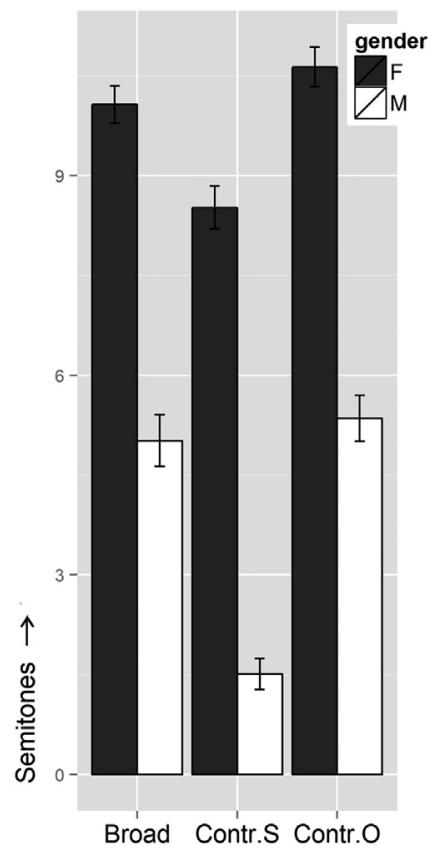

Fig. 1. Means and standard error bars of the fo minimum before the peak on the object (in semitones) for the three focus conditions.

\section{Results}

All speakers used prosodic features to mark differences in focus structure. In general, according to ToDI (Transcription of Dutch Intonation; Gussenhoven, 2005b), the nuclear pitch accent can be described as a fall $(\mathrm{H} * \mathrm{~L})$, whereas the shape of the sentence-initial prenuclear accent was dependent on the focus condition; $\mathrm{H} * \mathrm{~L}$ was used in the conTR.S condition, whereas a prenuclear rise $(\mathrm{L} * \mathrm{H})$ was often realized in the BROAD and CONTR. $O$ conditions.

To consider research question 1 ('How do Dutch L1 speakers and Turkish heritage speakers mark focus in Dutch?'), differences between focus conditions observed for both groups are described in Section 3.1. Subsequently, following research question 2a ('Are there differences in focus marking between the bilinguals and L1 speakers?'), the prosodic features that revealed differences between the bilinguals and the controls are described in Section 3.2. We return to research question $2 b$ ('Can such differences be attributed to Turkish?') in the discussion. Sections 3.1 and 3.2 both pertain to f0 movements, peak alignment, and duration differences. Graphs with means and error bars and statistical effects highlight the main findings described in the text. Additional descriptive statistics ( $N$, means, and standard deviations) for all measurements with significant results are given in Appendix $\mathrm{C}$.

\subsection{How do Dutch L1 speakers and Turkish heritage speakers mark focus in Dutch?}

In this section, we describe how both Dutch L1 speakers and Turkish heritage speakers phonetically mark sentence-initial and sentence-final constituents in broad and contrastive focus in semi-spontaneous speech, summarizing significant differences across focus conditions for both groups.
Table 3

Effects on the fo minimum before the peak on the object.

\begin{tabular}{|c|c|c|c|c|}
\hline & Fixed effect & $\beta$ & $t(\mathrm{df})$ & $p$ \\
\hline \multirow[t]{5}{*}{$\begin{array}{l}\text { Minimum } \\
\text { before peak }\end{array}$} & $\begin{array}{l}\text { Contr.S (intercept: } \\
\text { Broad) }\end{array}$ & -1.75 & $\begin{array}{l}-6.33 \\
(809.5)\end{array}$ & $<.0001$ \\
\hline & $\begin{array}{l}\text { Contr.S (intercept: } \\
\text { Contr.O) }\end{array}$ & -2.30 & $\begin{array}{l}-8.64 \\
(809.6)\end{array}$ & $<.0001$ \\
\hline & Gender & -5.41 & $\begin{array}{l}-3.51 \\
(14.7)\end{array}$ & $<.01$ \\
\hline & $\begin{array}{l}\text { Gender } * \text { Contr.S } \\
\text { (intercept: Broad) }\end{array}$ & -1.69 & $\begin{array}{l}-4.39 \\
(810.1)\end{array}$ & $<.0001$ \\
\hline & $\begin{array}{l}\text { Gender } * \text { Contr.S } \\
\text { (intercept: Contr.O) }\end{array}$ & -1.40 & $\begin{array}{l}-3.74 \\
(809.9)\end{array}$ & $<.001$ \\
\hline
\end{tabular}

\subsubsection{FO movements}

3.1.1.1. FO minimum before the peak on the object. The model for the minimum before the peak on the object shows that male speakers produced lower values for the minimum before the peak on the object in general, probably due to intrinsic differences between male and female speech. Furthermore, the minimum before the peak on the object was significantly lower for the CONTR.S condition than for the BROAD and CONTR.O conditions (Fig. 1; Table 3). Given that the object is the final word in the sentence and thus follows the subject, a lower minimum on the object in the CONTR.S condition suggests postfocal pitch reduction or deaccenting after the word in contrastive focus.

3.1.1.2. FO movements on the subject. Regarding the slope of the rise on the subject, the model reflects that the rise on the subject was less steep in the conTR.O condition than in the BROAD and CONTR.S conditions (Fig. 2; Table 4). This indicates prefocal pitch reduction to mark contrastive focus on sentencefinal word.

Regarding the fo minimum after the peak on the subject, it was highest in the BROAD condition (Fig. 2; Table 4). Furthermore, it was significantly lower in CONTR.S than in BROAD and CONTR.O, indicating a reduction in pitch following the word in contrastive focus.

Regarding the fall on the subject, there was a larger fall in pitch on the subject in the CONTR.S condition than in the BROAD and CONTR.O conditions (Fig. 2; Table 4). Additionally, the fall was significantly larger in the BROAD condition than in the CONTR. O condition. The smaller fall on the subject in the ConTR.O condition can also be explained by prefocal pitch reduction.

Regarding the slope of the fall on the subject, the fall on the subject was not only larger, but also steeper in the CoNTR.S condition compared to the BROAD and CONTR.O conditions (Fig. 2; Table 4), indicating that the speakers used a timecompressed pitch movement on the subject to signal contrastive focus on this word.

\subsubsection{Peak alignment}

Regarding peak location on the subject, the model reflects that peak alignment was significantly earlier in the CONTR.S than in the BROAD and CONTR.O conditions (Fig. 3; Table 5). The peak on the subject in the CONTR.S condition generally fell within the stressed syllable, whereas the peak fell more often in the posttonic syllable in the BROAD and CONTR.O conditions. 


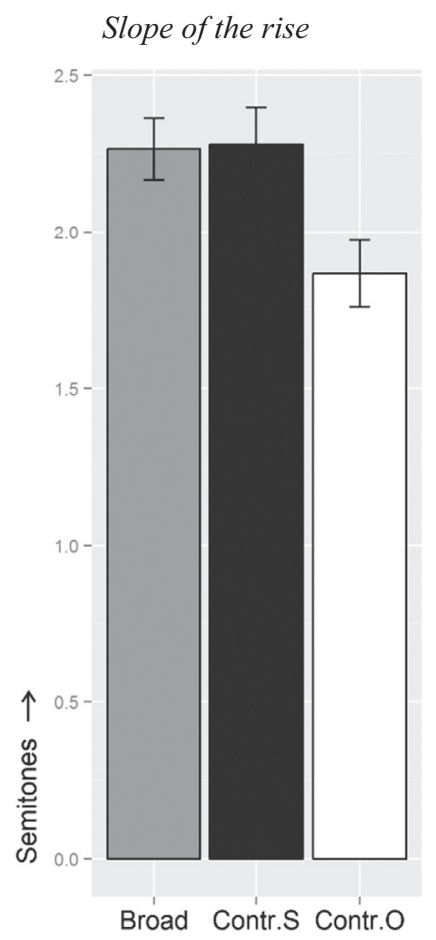

Minimum after peak

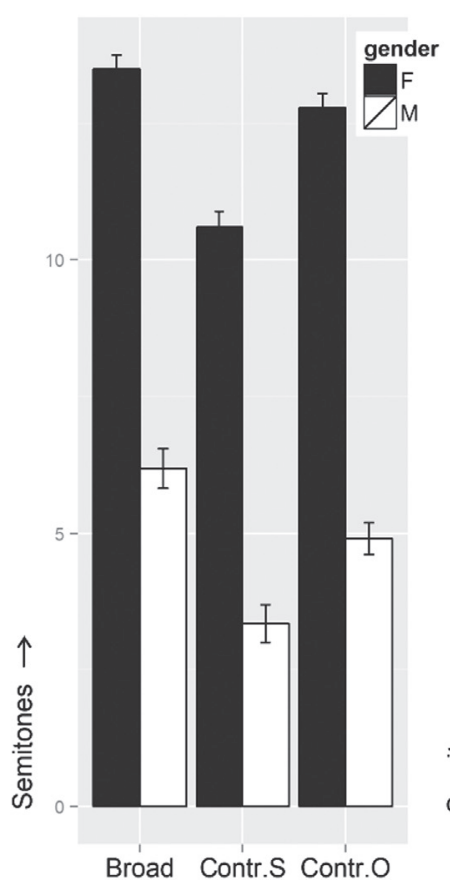

Fall

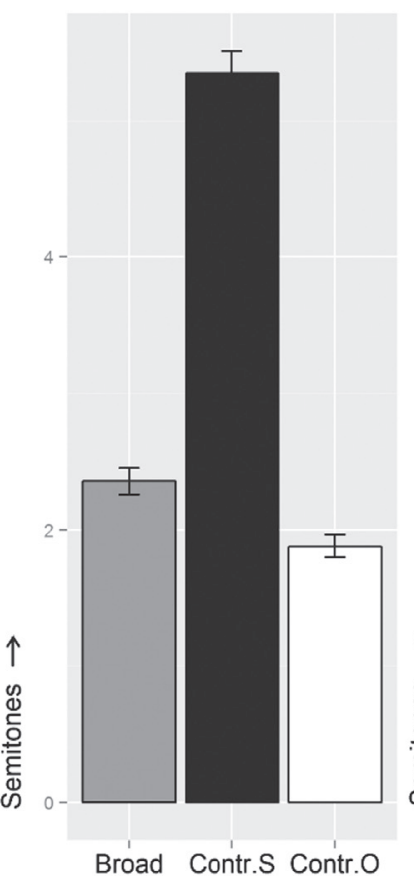

Slope of the fall

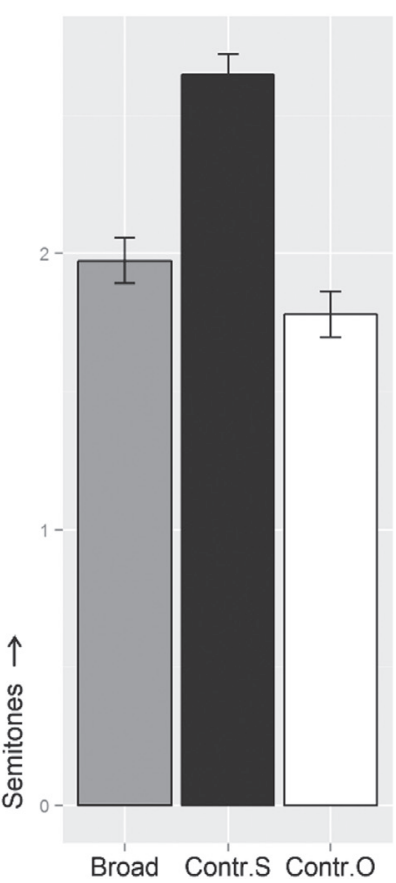

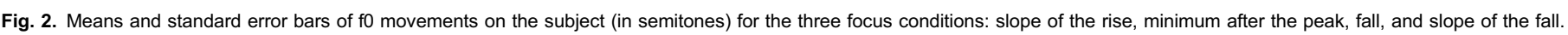

Table 4

Effects on f0 movements on the subject.

\begin{tabular}{|c|c|c|c|c|}
\hline & Fixed effect & $\beta$ & $t(\mathrm{df})$ & $p$ \\
\hline \multirow[t]{2}{*}{ Slope rise } & Contr.O (intercept: Broad) & -0.50 & $-3.93(812.4)$ & $<.0001$ \\
\hline & Contr.S (intercept: Contr.O) & 0.44 & $3.64(812)$ & $<.001$ \\
\hline \multirow[t]{5}{*}{ Minimum after peak } & Contr.O (intercept: Broad) & -0.76 & $-3.13(811.3)$ & $<.01$ \\
\hline & Contr.S (intercept: Broad) & -3.02 & $-12.74(810.6)$ & $<.0001$ \\
\hline & Contr.S (intercept: Contr.O) & -2.27 & $-9.73(809.9)$ & $<.0001$ \\
\hline & Gender & -7.45 & $-4.93(14.6)$ & $<.001$ \\
\hline & Gender * Contr.S (intercept: Contr.O) & 0.93 & $2.79(810.5)$ & $<.01$ \\
\hline \multirow[t]{3}{*}{ Fall } & Contr.O (intercept: Broad) & -0.55 & $-3.41(815.2)$ & $<.001$ \\
\hline & Contr.S (intercept: Broad) & 2.94 & $18.6(814.9)$ & $<.0001$ \\
\hline & Contr.S (intercept: Contr.O) & 3.49 & $22.81(813.5)$ & $<.0001$ \\
\hline \multirow[t]{2}{*}{ Slope fall } & Contr.S (intercept: Broad) & 0.69 & $6.84(813)$ & $<.0001$ \\
\hline & Contr.S (intercept: Contr.O) & 0.90 & $9.18(811.8)$ & $<.0001$ \\
\hline
\end{tabular}

The differences between the focus conditions for peak alignment and fo movements are illustrated in Fig. 4, which presents the pitch contours from a female L1 speaker of Dutch: The rise on the subject is steeper, peak alignment is earlier, the minimum after the peak is lower, and the fall is larger and steeper in CONTR.S than in the other conditions.

\subsubsection{Duration}

The stressed syllable of the subject had a significantly longer duration in the BROAD condition than in the CONTR.S and CONTR.O conditions (Fig. 5; Table 6). For total duration of the subject, all speakers shortened the subject significantly more in the CoNTR. $\mathrm{O}$ condition than in the BROAD and CONTR.S conditions (Fig. 5; Table 6).

The relative duration of the subject (the duration of the stressed syllable divided by the total duration of the word) was significantly longer in the CONTR.O condition than in the BROAD and CONTR.S conditions (Fig. 5; Table 6). Given that the stressed syllable and total word were shortest in CONTR.O, a longer relative duration suggests that the speakers shortened the posttonic syllable rather than lengthening the stressed syllable.

Concerning the duration of the stressed syllable of the object, again that duration was shortest when the other word was in contrastive focus, whereas it was longer in the CONTR.O condition (Fig. 5; Table 6). This points towards a strategy to shorten words that are not in contrastive focus, but contain repeated information.

Regarding the total duration of the object, the final word in the CONTR.S condition was significantly shorter than in the BROAD and CONTR.O conditions, again indicating the shortening of repeated words (Fig. 5; Table 6). Although the incorporation of gender in the model led to an improvement, the effect itself was not below the significance level of .0167 .

Regarding the relative duration difference between subject and object, the model reveals that it is the largest in the CONTR.O condition. The positive values for the mean in all focus 


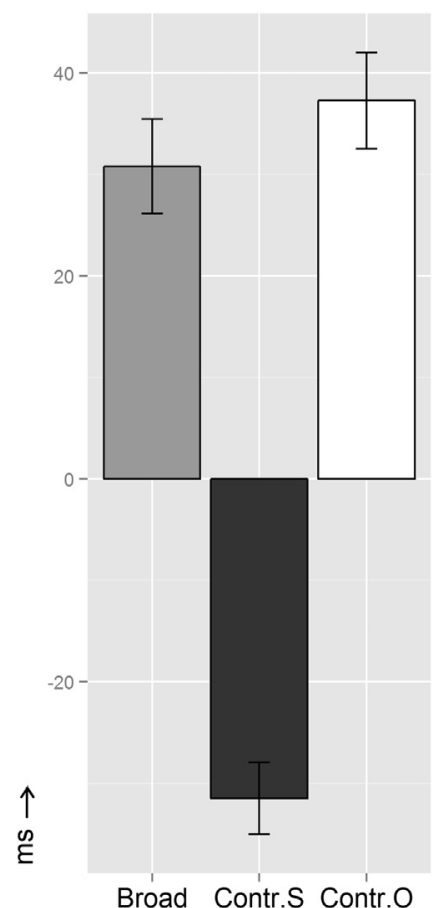

Fig. 3. Means and standard error bars for peak location on the subject (in ms, relative to the end of the stressed syllable) for the three focus conditions.

Table 5

Effects on peak location on the subject.

\begin{tabular}{|c|c|c|c|c|}
\hline & Fixed effect & $\beta$ & $t(\mathrm{df})$ & $p$ \\
\hline \multirow[t]{2}{*}{ Peak location } & $\begin{array}{l}\text { Contr.S (intercept: } \\
\text { Broad) }\end{array}$ & -66.49 & $\begin{array}{l}-12.7 \\
(815.1)\end{array}$ & $<.0001$ \\
\hline & $\begin{array}{l}\text { Contr.S (intercept: } \\
\text { Contr.O) }\end{array}$ & -69.35 & $\begin{array}{l}-13.64 \\
(814.5)\end{array}$ & $<.0001$ \\
\hline
\end{tabular}
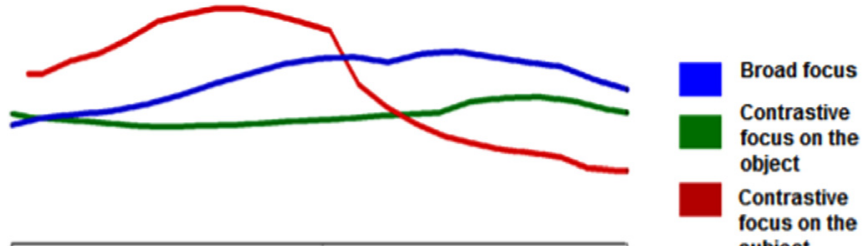

\begin{tabular}{|c|c|}
\hline MOE & der \\
\hline & MOEder \\
\hline S \\
\hline
\end{tabular}

Fig. 4. Pitch contours (in Hertz) from a Dutch female from the control group uttering the sentence-initial subject (S) moeder, 'mother' in the three focus conditions.

conditions indicate that the relative duration of the subject is longer than the relative duration of the object (Fig. 5; Table 6). Given that a longer relative duration would indicate a longer stressed syllable compared to the duration of the posttonic syllable(s), it might also reveal that the part after the stressed syllable is shortened. As shown in Section 3.2.3 for the durational difference between subject and object, this is indeed

the case: The object is longer than the subject in all conditions, and longest when this object is in the CONTR.O condition. Longer relative durations for the subject thus indicate shorter posttonic syllables. Therefore, the posttonic syllables of the subject were the shortest in CONTR.O.

Summarizing, both groups showed a time-compressed pitch movement on the subject in the CONTR.S condition and prefocal pitch reduction in the CONTR.O condition. Furthermore, the stressed syllable of the subject was longest in the BROAD condition, and repeated words were shortened.

\subsection{Are there differences in focus marking between the bilinguals and L1 speakers?}

In this section, we describe the prosodic differences between the two groups of speakers to explore a potential Turkish influence in the bilinguals' Dutch prosody.

\subsubsection{FO movements}

3.2.1.1. FO movements on the subject. For the bilinguals, the f0 minimum before the peak on the subject in the CoNTR.S condition was significantly higher than in the BROAD and CONTR.O conditions (Fig. 6; Table 7). The L1 speakers of Dutch did not show a large difference between BROAD, ConTR. $\mathrm{S}$, and CONTR.O. The difference was particularly clear for the female speakers: While the Turkish-Dutch female bilinguals used a higher minimum before the peak to signal contrastive focus, the female L1 speakers of Dutch did not show a difference across the focus conditions. Regarding the male speakers, the male bilinguals started a bit lower than the male L1 speakers of Dutch in general. However, the difference between BROAD and CONTR.S for the male bilinguals was larger than for the male L1 speakers of Dutch.

Regarding the rise on the subject, the L1 speakers of Dutch employed a larger rise in the Contr.S than in the CoNTR.O condition, whereas the Turkish-Dutch bilinguals used a larger rise on the subject in the CoNTR.O than in the ConTR.S condition (Fig. 6; Table 7). For all speakers the rise on the subject was largest in the BROAD condition, which can be explained by the later peak alignment in this condition compared to the CoNTR.S condition.

Concerning the peak on the subject, the Turkish-Dutch bilinguals realized a significantly higher peak in the CoNTR.S than in the BROAD condition, while the L1 speakers of Dutch realized somewhat higher peaks in the BROAD than in the CONTR. $S$ condition. Moreover, while the peak on the subject was higher in all conditions for the Turkish-Dutch female bilinguals compared to the female L1 speakers of Dutch, it was lower for the Turkish-Dutch male bilinguals than for the male L1 speakers of Dutch (Fig. 6; Table 7).

3.2.1.2. FO movements on the object. Regarding the rise on the object, the model shows that all speakers used a smaller rise in the CoNTR.S condition (Fig. 7; Table 8), indicating postfocal pitch reduction. Furthermore, the Dutch $\mathrm{L} 1$ speakers realized a larger rise on the object in the CONTR.O than in the BROAD condition. Although the rise on the object for the Turkish-Dutch bilinguals was a bit larger on the object in the CONTR.O condition than in the BROAD condition, the difference between conditions was much smaller than for the Dutch L1 speakers. This suggests 


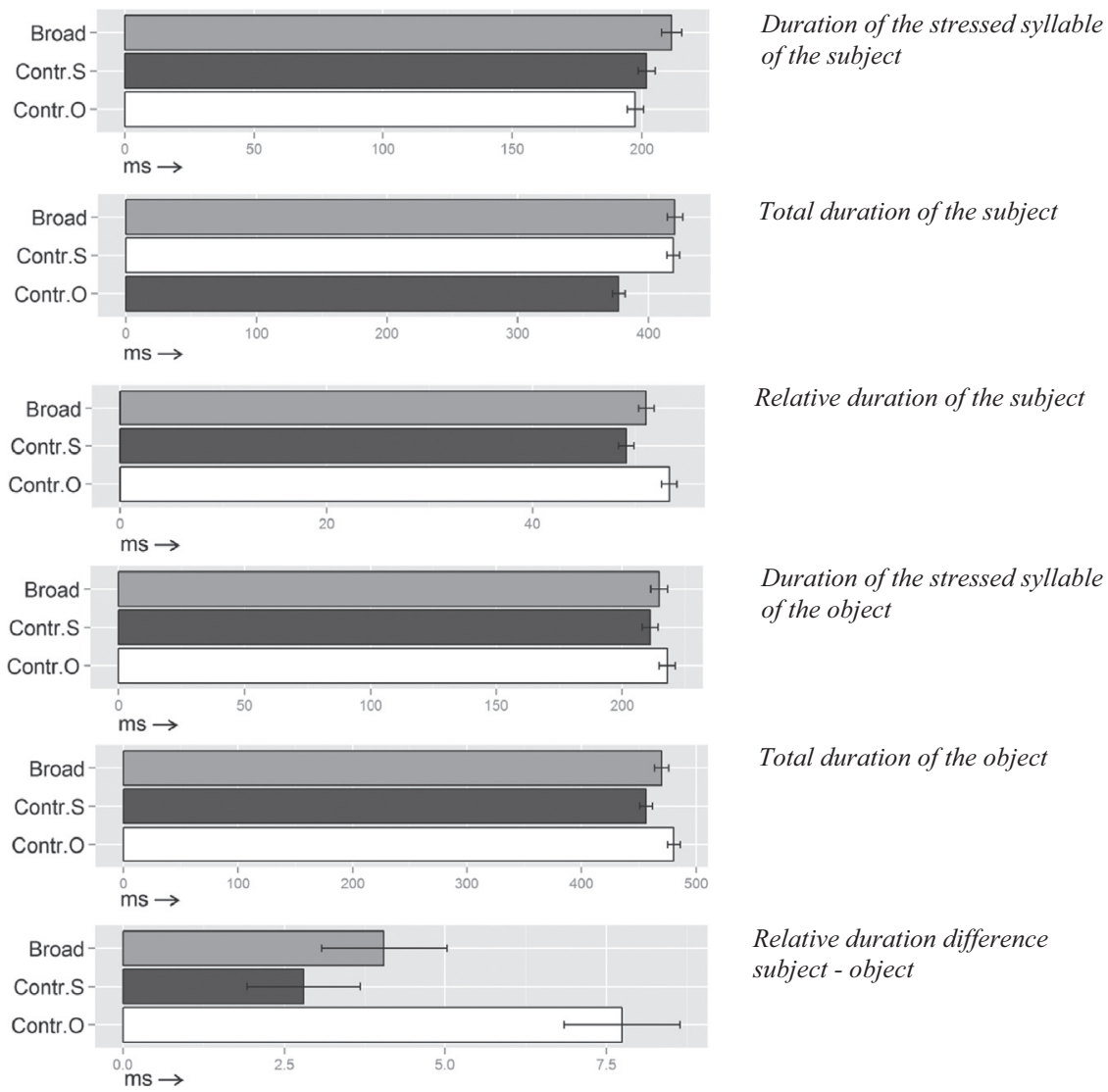

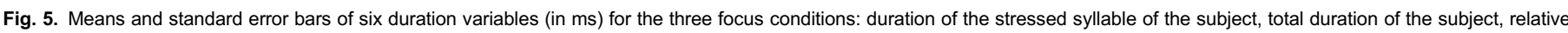
duration of the subject, duration of the stressed syllable of the object, total duration of the object, and relative duration difference between subject and object.

Table 6

Effects on duration.

\begin{tabular}{|c|c|c|c|c|}
\hline & Fixed effect & $B$ & $t(\mathrm{df})$ & $p$ \\
\hline \multirow[t]{2}{*}{ Duration of the stressed syllable of the subject } & Contr.O (intercept: Broad) & -11.50 & $-4.82(828.3)$ & $<.0001$ \\
\hline & Contr.S (intercept: Broad) & -6.38 & $-2.73(828.8)$ & $<.01$ \\
\hline \multirow[t]{2}{*}{ Total duration of the subject } & Contr.O (intercept: Broad) & -55.97 & $-8.28(825.7)$ & $<.0001$ \\
\hline & Contr.S (intercept: Contr.O) & 49.06 & $7.79(825.3)$ & $<.0001$ \\
\hline \multirow[t]{3}{*}{ Relative duration of the subject } & Contr.O (intercept: Broad) & 3.06 & $5.57(827.7)$ & $<.0001$ \\
\hline & Contr.S (intercept: Contr.O) & -3.63 & $-6.97(827.5)$ & $<.0001$ \\
\hline & Contr.S (intercept: Contr.O) & -7.69 & $-3.88(810.2)$ & $<.001$ \\
\hline \multirow[t]{3}{*}{ Total duration of the object } & Contr.S (intercept: Broad) & -15.55 & $-3.48(810.4)$ & $<.001$ \\
\hline & Contr.S (intercept: Contr.O) & -25.69 & $-5.89(810.4)$ & $<.0001$ \\
\hline & Gender & -64.84 & $-3.04(14)$ & $<.01$ \\
\hline \multirow[t]{2}{*}{ Relative durationdiff } & Contr.O (intercept: Broad) & 3.68 & $4.69(716.2)$ & $<.0001$ \\
\hline & Contr.S (intercept: Contr.O) & -4.20 & $-5.76(715.1)$ & $<.0001$ \\
\hline
\end{tabular}

that the bilinguals did not use a larger rise to signal contrastive focus, which is comparable to the findings for the subject.

Similar to the peak on the subject, the Turkish-Dutch female bilinguals realized a higher peak on the object than the female Dutch L1 speakers, in all focus conditions (Fig. 7; Table 8). For the male speakers, the difference was somewhat smaller, although the Turkish-Dutch male bilinguals realized the peak on the object somewhat lower than the male Dutch L1 speakers. Moreover, whereas for the peak on the subject only the TurkishDutch bilinguals produced higher peaks in the CoNTR.S than in the BROAD condition, the Dutch L1 speakers showed larger differences for the peak on the object. That is, the Dutch L1 speakers realized a higher peak on the object in the CoNTR.O than in the BROAD condition. The peak on the object in the CONTR. $\mathrm{O}$ condition for the Turkish-Dutch bilinguals was also somewhat higher compared to the BROAD condition, but the difference is smaller, particularly for the Turkish-Dutch male bilinguals.

Regarding the fall on the object, in general, all speakers used a smaller fall in the CONTR.S condition than in the BROAD and CONTR.O conditions (Fig. 8; Table 8), again indicating postfocal pitch reduction. In addition, male speakers seemed to employ larger falls than female speakers, except in CoNTR.S. This difference was particularly clear in the BROAD condition. Furthermore, the Turkish-Dutch male bilinguals employed an equally large fall on the object in the BROAD and CONTR.O condition, whereas all other speakers realized larger falls in the CONTR.O 
F0 minimum before peak

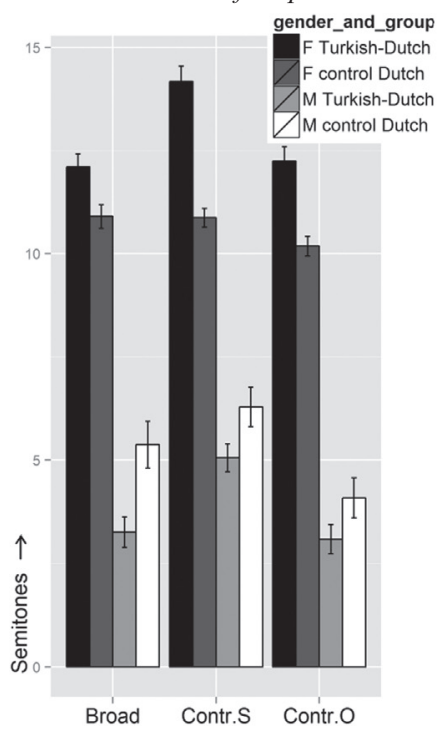

Rise

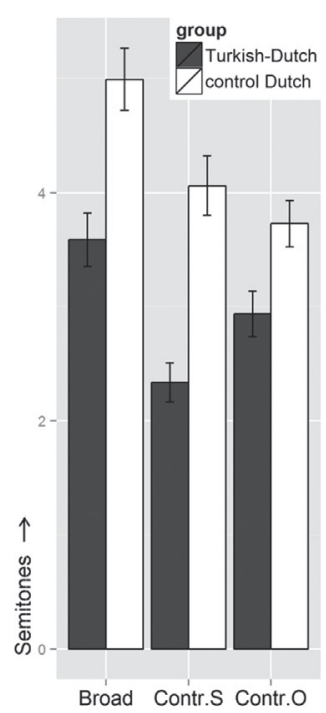

Peak

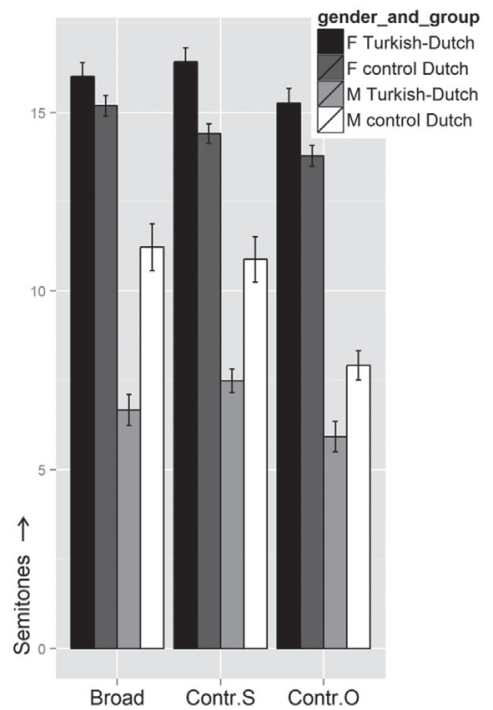

Fig. 6. Means and standard error bars of the fo movements on the subject for the three focus conditions (in semitones): minimum before the peak, rise, and the peak.

Table 7

Effects on f0 movements on the subject.

\begin{tabular}{|c|c|c|c|c|}
\hline & Fixed effect & $\beta$ & $t(\mathrm{df})$ & $p$ \\
\hline \multirow[t]{5}{*}{ Minimum before peak } & Group * Contr.S (intercept: Broad) & 1.87 & $4.06(807.9)$ & $<.0001$ \\
\hline & Group * Contr.S (intercept: Contr.O) & 1.29 & $2.84(807.6)$ & $<.01$ \\
\hline & Gender & -6.19 & $-3.57(12.7)$ & $<.01$ \\
\hline & Gender * Contr.S (intercept: Broad) & 1.36 & $2.93(807.5)$ & $<.01$ \\
\hline & Gender * Contr.S (intercept: Contr.O) & 1.88 & $4.27(807.4)$ & $<.0001$ \\
\hline \multirow[t]{3}{*}{ Rise } & Contr.O (intercept: Broad) & -1.39 & $-6.12(811)$ & $<.0001$ \\
\hline & Contr.S (intercept: Broad) & -0.97 & $-4.32(811.6)$ & $<.0001$ \\
\hline & Group * Contr.S (intercept: Contr.O) & -1.16 & $-3.67(810.5)$ & $<.001$ \\
\hline \multirow[t]{7}{*}{ Peak } & Contr.O (intercept: Broad) & -1.33 & $-5.46(809.6)$ & $<.0001$ \\
\hline & Contr.S (intercept: Broad) & -0.83 & $-3.46(809.4)$ & $<.001$ \\
\hline & Group * Contr.S (intercept: Broad) & 1.01 & $2.89(809.3)$ & $<.01$ \\
\hline & Gender * Contr.O (intercept: Broad) & -1.86 & $-5.21(808.3)$ & $<.0001$ \\
\hline & Gender $*$ Contr.S (intercept: Contr.O) & 2.96 & $8.87(807.5)$ & $<.0001$ \\
\hline & Group $*$ Gender $*$ Contr.O (intercept: Broad) & 1.66 & $3.19(808.8)$ & $<.01$ \\
\hline & Group * Gender * Contr.S (intercept: Contr.O) & -2.58 & $-5.21(809.9)$ & $<.0001$ \\
\hline
\end{tabular}

Rise

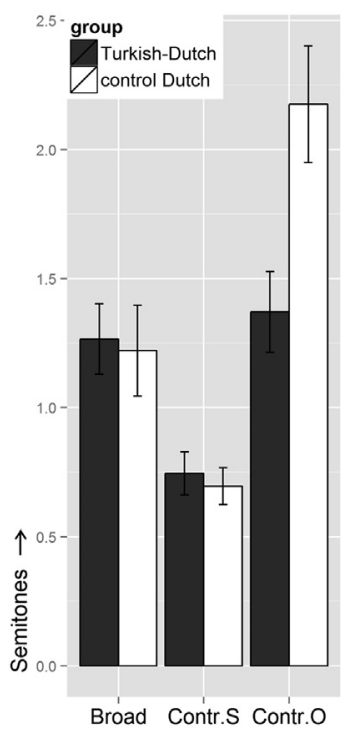

\section{Peak}

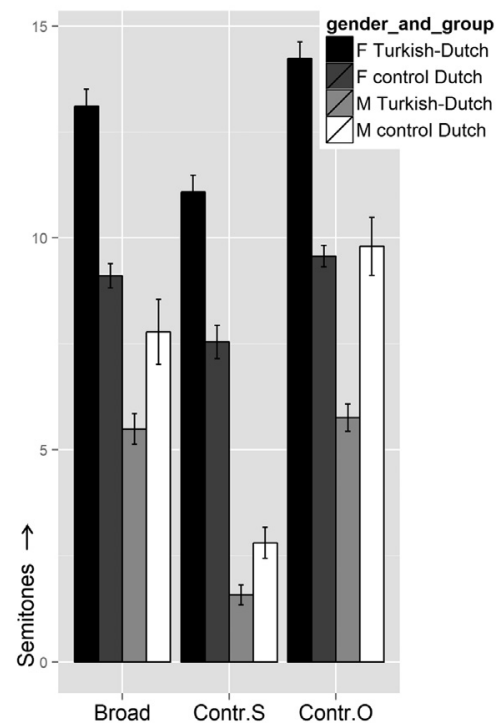

Fig. 7. Means and standard error bars of the rise and peak (in semitones) on the object for the three focus conditions.

than in the BROAD condition. Moreover, the difference between the CONTR.O condition on the one hand and the BROAD and CONTR.S conditions on the other hand was larger for the Turkish-Dutch female bilinguals than for the female L1 speakers of Dutch.

Regarding the slope of the fall on the object, the slope of the fall realized by the Turkish-Dutch male bilinguals was equally steep in the BROAD and CONTR.O conditions, whereas all other speakers showed a steeper slope for the CONTR.O than for the BROAD condition (Fig. 8; Table 8). In other words, all speakers except for the Turkish-Dutch male speakers marked contrastive focus on the object with a steeper slope.

3.2.1.3. Peak range. The model shows a difference in declination between the Turkish-Dutch bilinguals and the Dutch L1 speakers (Fig. 9; Table 9). The difference was particularly clear in the BROAD condition: While the L1 speakers of Dutch showed a large difference between the peak on the subject and on the object, this difference was much smaller for the Turkish-Dutch bilinguals, who remained more at the same pitch level throughout the sentence. The difference in height between the peak on the subject and the 
Table 8

Effects on f0 movements on the object.

\begin{tabular}{|c|c|c|c|c|}
\hline & Fixed effect & $\beta$ & $t(\mathrm{df})$ & $p$ \\
\hline \multirow[t]{5}{*}{ Rise } & Contr.O (intercept: Broad) & 0.88 & $5.29(804.6)$ & $<.0001$ \\
\hline & Contr.S (intercept: Broad) & -0.58 & $-3.45(804.4)$ & $<.001$ \\
\hline & Contr.S (intercept: Contr.O) & -1.46 & $-8.95(804.1)$ & $<.0001$ \\
\hline & Group * Contr.O (intercept: Broad) & -0.79 & $-3.18(804.7)$ & $<.01$ \\
\hline & Group * Contr.S (intercept: Contr.O) & 0.81 & $3.34(804.7)$ & $<.001$ \\
\hline \multirow[t]{8}{*}{ Peak } & Contr.S (intercept: Broad) & -1.50 & $-4.41(800.8)$ & $<.0001$ \\
\hline & Contr.S (intercept: Contr.O) & -2.04 & $-6.21(802.1)$ & $<.0001$ \\
\hline & Group * Contr.S (intercept: Contr.O) & -1.26 & $-2.6(801.9)$ & $<.01$ \\
\hline & Gender * Contr.O (intercept: Broad) & 1.49 & $3.17(803.8)$ & $<.01$ \\
\hline & Gender * Contr.S (intercept: Broad) & -3.28 & $-6.95(800.9)$ & $<.0001$ \\
\hline & Gender $*$ Contr.S (intercept: Contr.O) & -4.78 & $-10.37(802)$ & $<.0001$ \\
\hline & Group $*$ Gender * Contr.O (intercept: Broad) & -2.58 & $-3.67(805.3)$ & $<.001$ \\
\hline & Group $*$ Gender $*$ Contr.S (intercept: Contr.O) & 3.97 & $5.81(802.6)$ & $<.0001$ \\
\hline \multirow[t]{8}{*}{ Fall } & Contr.S (intercept: Broad) & -1.20 & $-3.58(797.6)$ & $<.001$ \\
\hline & Contr.S (intercept: Contr.O) & -1.72 & $-5.24(798.6)$ & $<.0001$ \\
\hline & Gender (intercept: Contr.O) & 5.30 & $3.26(12.6)$ & $<.01$ \\
\hline & Group * Contr.S (intercept: Contr.O) & -1.58 & $-3.29(798.5)$ & $<.01$ \\
\hline & Gender * Contr.S (intercept: Broad) & -3.80 & $-8.11(797.6)$ & $<.0001$ \\
\hline & Gender $*$ Contr.S (intercept: Contr.O) & -5.01 & $-10.96(798.5)$ & $<.0001$ \\
\hline & Group * Gender * Contr.O (intercept: Broad) & -2.97 & $-4.24(802.3)$ & $<.0001$ \\
\hline & Group $*$ Gender $*$ Contr.S (intercept: Contr.O) & 4.38 & $6.47(799.2)$ & $<.0001$ \\
\hline \multirow[t]{6}{*}{ Fall slope } & Contr.S (intercept: Contr.O) & -0.44 & $-2.60(797.8)$ & $<.01$ \\
\hline & Gender (intercept: Contr.O) & 1.81 & $3.17(13.4)$ & $<.01$ \\
\hline & Gender * Contr.S (intercept: Broad) & -1.73 & $-7.11(797.1)$ & $<.0001$ \\
\hline & Gender $*$ Contr.S (intercept: Contr.O) & -2.30 & $-9.66(797.7)$ & $<.0001$ \\
\hline & Group * Gender * Contr.O (intercept: Broad) & -0.90 & $-2.47(800.6)$ & .0138 \\
\hline & Group * Gender * Contr.S (intercept: Contr.O) & 1.59 & $4.5(798.2)$ & $<.0001$ \\
\hline
\end{tabular}

Fall

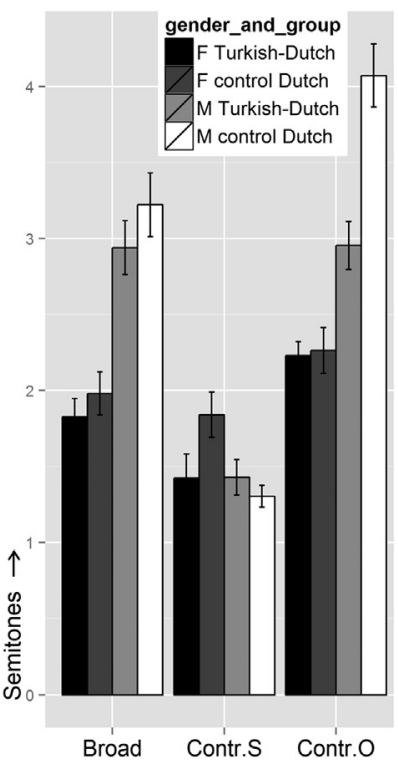

Slope of the fall

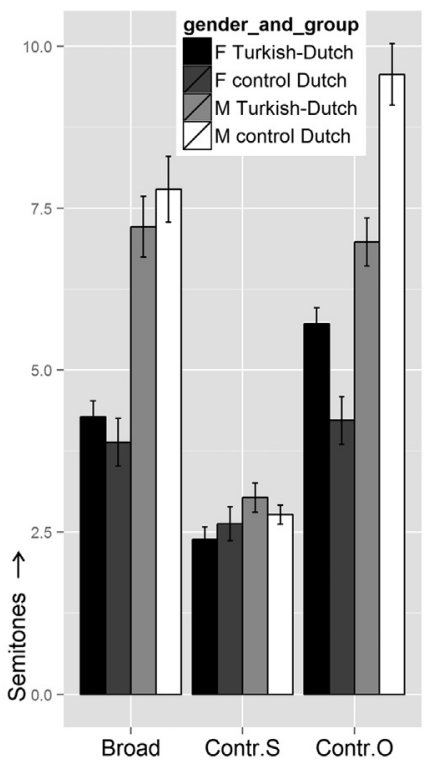

Fig. 8. Means and standard error bars of the fall and slope of the fall (in semitones) on the object for the three focus conditions.

object is substantially larger for the female Dutch L1 speakers than for the female bilinguals. This also follows from the finding, mentioned above, that the peak on the object was significantly higher for the female bilinguals than for the female Dutch L1 speakers. The male Dutch L1 speakers also showed more declination in the BROAD condition than the TurkishDutch male bilinguals. Unlike for the female speakers, however, the difference for the male speakers arises because

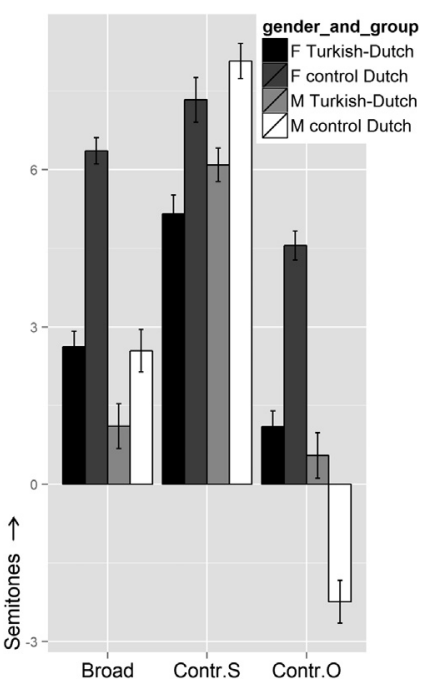

Fig. 9. Means and standard error bars of the difference (in semitones) between the peak on the subject and the peak on the object, for the three focus conditions.

the Turkish-Dutch male bilinguals realized a lower peak on the subject than the male Dutch L1 speakers. This led them to continue at the same pitch level when realizing the peak on the object. The differences between the female bilinguals and female L1 speakers of Dutch on the one hand, and between the male bilinguals and male L1 speakers of Dutch on the other hand, are illustrated by the pitch contours of broad focus sentences in Figs. 10 and 11, respectively. Whereas the Turkish-Dutch female bilingual used a higher peak on the object to maintain the same pitch level throughout the sentence, the limited peak range of the Turkish-Dutch male 
Table 9

Effects on peak range.

\begin{tabular}{|c|c|c|c|c|}
\hline & Fixed effect & $\beta$ & $t(\mathrm{df})$ & $p$ \\
\hline \multirow[t]{12}{*}{ Peak range } & Contr.O (intercept: Broad) & -1.78 & $-3.87(709)$ & $<.001$ \\
\hline & Contr.S (intercept: Contr.O) & 2.69 & $6.08(707.1)$ & $<.0001$ \\
\hline & Group & -3.84 & $-4.26(20.2)$ & $<.001$ \\
\hline & Gender & -3.57 & $-3.99(19.6)$ & $<.001$ \\
\hline & Group * Gender (intercept: Contr.O) & 6.12 & $4.92(18.1)$ & $<.001$ \\
\hline & Group $*$ Contr.S (intercept: Broad) & 1.7 & $2.46(711.8)$ & .0143 \\
\hline & Gender * Contr.S (intercept: Broad) & 4.52 & $6.83(706.6)$ & $<.0001$ \\
\hline & Gender * Contr.O (intercept: Broad) & -3.10 & $-4.63(707.7)$ & $<.0001$ \\
\hline & Gender $*$ Contr.S (intercept: Contr.O) & 7.62 & $12.39(706.6)$ & $<.0001$ \\
\hline & Group * Gender * Contr.S (intercept: Broad) & -2.55 & $-2.62(709.7)$ & $<.01$ \\
\hline & Group * Gender * Contr.O (intercept: Broad) & 3.70 & $3.72(711)$ & $<.001$ \\
\hline & Group * Gender * Contr.S (intercept: Contr.O) & -6.26 & $-6.77(709.8)$ & $<.0001$ \\
\hline
\end{tabular}

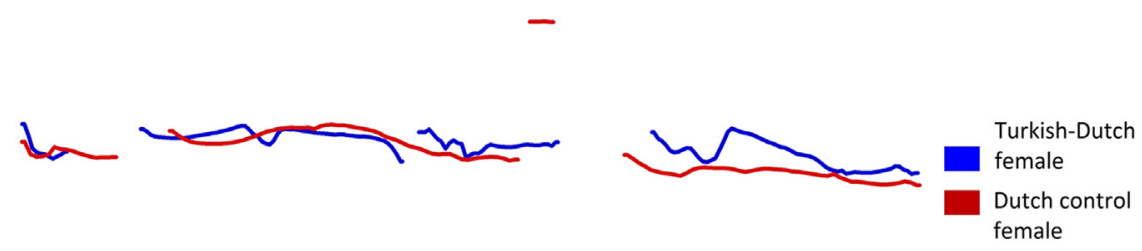

\begin{tabular}{|c|c|c|c|c|c|c|}
\hline de & VA & der & wast & de & $\mathrm{HON}$ & den \\
\hline de & \multicolumn{2}{|c|}{ VAder } & wast & de & \multicolumn{2}{|c|}{ HONden } \\
\hline art & \multicolumn{2}{|c|}{$\mathrm{S}$} & V & art & \multicolumn{2}{|c|}{$\mathrm{O}$} \\
\hline
\end{tabular}

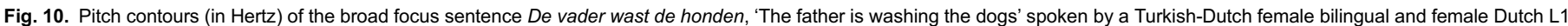
speaker from the control group.

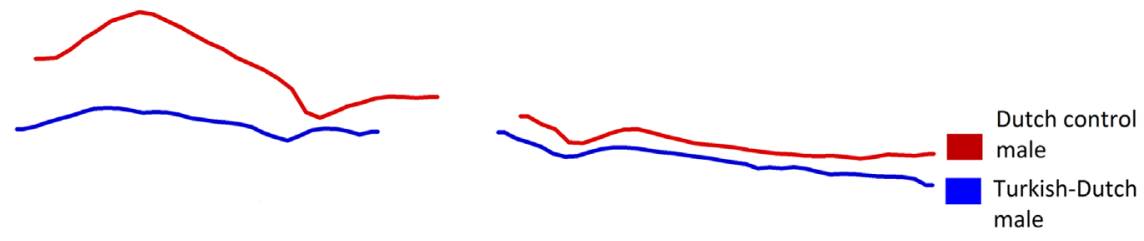

\begin{tabular}{|c|c|c|c|c|}
\hline O & wast & de & RA & men \\
\hline \multicolumn{2}{|c|}{ ma } & wast & de & RAmen \\
\hline \multicolumn{2}{|c|}{ Oma } & V & art & O \\
\hline \multicolumn{2}{|c|}{$\mathrm{S}$} & V
\end{tabular}

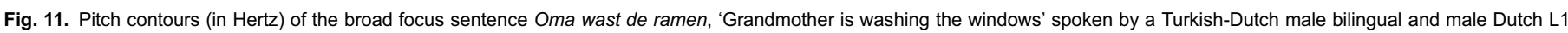
speaker from the control group.

bilingual is due to the lower peak at the beginning of the utterance than that of the control group.

\subsubsection{Peak alignment}

3.2.2.1. Peak location on the object. In the model, there was a difference between the Turkish-Dutch bilinguals and the L1 speakers of Dutch. Although the peak fell within the stressed syllable in all conditions, which is typical of the $\mathrm{H} * \mathrm{~L}$ nuclear pitch accent, the bilinguals realized the peak significantly earlier in the CONTR.O condition than in the BROAD condition, whereas the Dutch L1 speakers showed the opposite pattern, with earlier alignment for the BROAD condition than for the CONTR.O condition (Fig. 12; Table 10).

\subsubsection{Duration}

Regarding the total duration difference, all speakers used longer durations for the object than for the subject, which can be attributed to final lengthening (Fig. 13; Table 11). Furthermore, the object is relatively longer (as compared to the subject) in the CONTR.O condition than in the BROAD and CONTR.S conditions (Table 20). However, the Turkish-Dutch bilinguals used more final lengthening in the BROAD and CONTR.S conditions than the Dutch L1 speakers. In other words, the final word of the TurkishDutch bilinguals was longer relative to the subject than the final word of the Dutch L1 speakers in these conditions. Moreover, the L1 speakers of Dutch shortened the object in the CoNTR.S condition, while the Turkish-Dutch bilinguals did not mark the difference between the BROAD and CONTR.S conditions by means of duration differences of the object. 


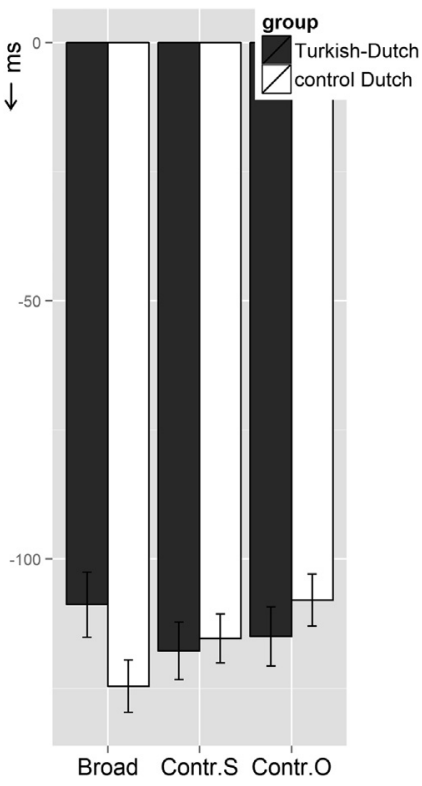

Fig. 12. Means and standard error bars of peak location (in $\mathrm{ms}$, relative to the end of the stressed syllable) on the object for the three focus conditions.

Table 10

Effects on peak location on the object.

\begin{tabular}{lllll}
\hline & Fixed effect & $\beta$ & $t(\mathrm{df})$ & $p$ \\
\hline $\begin{array}{l}\text { Peak } \\
\text { location }\end{array}$ & $\begin{array}{l}\text { Contr.O (intercept: } \\
\text { Broad) }\end{array}$ & 16.22 & $2.97(803.7)$ & $<.01$ \\
& $\begin{array}{l}\text { Group } * \text { Contr.O } \\
\text { (intercept: Broad) }\end{array}$ & -21.60 & $\begin{array}{l}-2.65 \\
(804.2)\end{array}$ & $<.01$ \\
& & & \\
\hline
\end{tabular}

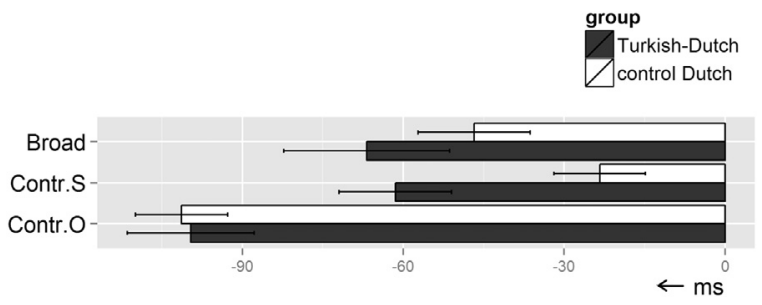

Fig. 13. Means and standard error bars of the total duration difference between the subject and object (in $\mathrm{ms}$ ), for the three focus conditions.

Table 11

Effects on total duration difference between subject and object.

\begin{tabular}{cllll}
\hline & Fixed effect & $\beta$ & $t(\mathrm{df})$ & $p$ \\
\hline $\begin{array}{l}\text { Total duration } \\
\text { subject - total }\end{array}$ & $\begin{array}{l}\text { Contr.O } \\
\text { (intercept: Broad) }\end{array}$ & -69.35 & $\begin{array}{l}-7.26 \\
(713)\end{array}$ & $<.0001$ \\
duration object & Contr.S (intercept: & 76.03 & $\begin{array}{l}8.64 \\
(712.4)\end{array}$ & $<.0001$ \\
& $\begin{array}{l}\text { Contr.O) } \\
\text { Group * Contr.O }\end{array}$ & 37.71 & $\begin{array}{l}2.67 \\
(713.2)\end{array}$ & $<.01$ \\
& (intercept: Broad) & & & \\
\hline
\end{tabular}

\section{Discussion and conclusion}

We examined the prosodic marking of focus in semispontaneous Dutch by eight Turkish-Dutch bilinguals and a control group of eight L1 speakers of Dutch. By determining the similarities and differences between the two groups, we established a potential influence from Turkish on the Dutch prosody of these heritage speakers of Turkish, suggesting that a weaker L1 affects the prosody of the dominant L2. Below, we discuss our findings on $\mathrm{fO}$ movements, peak alignment, and duration.

\subsection{How do Dutch L1 speakers and Turkish heritage speakers mark focus in Dutch?}

\subsubsection{FO movements}

Both Turkish-Dutch bilinguals and L1 speakers of Dutch marked contrastive focus on the subject with a lower f0 minimum after the peak on the subject, combined with a larger and steeper fall (i.e., a time-compressed pitch movement). Thus, the intonation of sentence-initial, preverbal constituents in contrastive focus in our study was similar to the nuclear accents in Hanssen et al. (2008), occurring later in the sentence. This has not been demonstrated before for Dutch. Furthermore, the object in the CONTR.S condition was characterized by a lower fo minimum before the peak, a smaller rise, a lower peak, and a smaller fall than in the other conditions. These findings indicate postfocal pitch reduction or deaccenting after the word in contrastive focus (Gussenhoven, 2005a). Finally, the rise on the subject was more gradual in the CONTR. $O$ condition than in the BROAD and CONTR.S conditions.

\subsubsection{Peak alignment}

Regarding peak alignment, all speakers marked contrastive focus on the subject with an early peak, while the peak on the subject generally fell in the posttonic syllable in the BROAD and CONTR.O conditions. The later peak alignment for the BROAD condition also accounts for the finding that both groups of speakers employed a larger rise on the subject in this condition. The late peak alignment on prenuclear accents in complete sentences in the BROAD and CONTR.O conditions, which can be described as a rise $(\mathrm{L} * \mathrm{H})$, is a novel finding regarding Dutch prosody. Although Ladd et al. (2000) found that peak alignment on prenuclear accents was affected by the vowel in the stressed syllable (i.e., somewhat later on short vowels than on long vowels), the peak fell within the stressed syllable in their study. This can possibly be explained by the location of the accent under study: Whereas we examined subjects in sentence-initial position, Ladd et al. (2000) concerned prenuclear accents on adjectives that did not occur sentenceinitially. Another explanation points at the difference between read speech in Ladd et al. and the semi-spontaneous nature of our data. In fact, Face (2003) also found differences in peak alignment between read speech and spontaneous speech for Spanish.

Our findings regarding the prenuclear rise on the subject in the CONTR.O condition do not correspond to Chen (2007). The subject in the CONTR.O condition is topic (given information that was introduced in the question), similar to the subjects in Chen, who also used question-answer pairs. However, Chen found a fall $(\mathrm{H} * \mathrm{~L})$ for sentence-initial topics. This suggests that the intonation of sentences in which the final word is in contrastive focus (our study) differs from that of sentences in which the final word is in neutral focus (Chen's study).

\subsubsection{Duration}

The stressed syllable of the subject was the longest in the BROAD condition. Both the duration of the stressed syllable and the 
total duration of the subject were the shortest in the CONTR.O condition. Likewise, the object was the shortest in the CONTR.S condition. Additionally, the relative duration of the subject (that is, duration of the stressed syllable divided by the duration of the word) was longer in the CONTR.O condition, indicating that durations of the posttonic syllables were also reduced. These findings show that topics were shorter than words in focus. Furthermore, the relative duration difference between the subject and object was also the largest in the ConTR.O condition, confirming that the posttonic syllables of the subject as compared to those of the object were also the shortest in this condition. Even though in the present study non-focal words were shortened, the stressed syllable of the subject in contrastive focus was shorter than in broad focus. This contrasts with Hanssen et al. (2008), who found longer durations for contrastive focus. The difference might be due to the somewhat more spontaneous character of our data relative to Hanssen et al. (2008), where the participants read sentences. Thus, the longer durations for broad focus we observed might reflect the speakers' need to consider the best way to describe a picture when answering the question: 'What is happening?'. This could result in a prosodic boundary after the subject. An utterance in contrastive focus, on the other hand, requires less time for sentence formulation, because it mainly repeats the question, except for the word in contrastive focus. This may account for the durational differences between the focus conditions in our study.

Importantly, the difference between the total duration of the subject and the object was the largest for all speakers in the CONTR.O condition. Again, this does not seem to point toward lengthening as a strategy to mark contrastive focus. Rather, the subject seemed to be shortened. One account of this observation refers to the informational status of the subject in CoNTR.O: The subject is repeated, given information, because it was already introduced in the question. The object, on the other hand, contains new, contrastive information. A further explanation lays in the perception of prominence, which depends on the prosodic context (Krahmer \& Swerts, 2001). An f0 peak followed by a peak of comparable height is perceived as less prominent than a peak followed by a lower peak. This account of pitch movements may be extended to durational differences: A shorter subject lends more prominence to the longer, final word in the sentence. Whether a word is lengthened or not might thus be determined by the prosodic context rather than by comparing it to the same word in a different context. In this perspective, all speakers in the present study used longer durations to signal contrastive focus on the object. This is in line with Chen (2009), who also found shorter durations for topics than for focused words.

To conclude, both groups in our study marked contrastive focus by a time-compressed pitch movement and used duration differences to indicate the informational status of words. All speakers showed late peak alignment of the subject in the BROAD and CONTR. O conditions, which has not been described for Dutch before.

\section{2. (a) Are there differences in focus marking between the bilinguals and L1 speakers? (b) Can such differences be attributed to Turkish??}

As was mentioned in the introduction, Dutch is a stress-accent language (e.g., Van Heuven, 2014), whereas Turkish has been classified as either a stress-accent or pitch-accent language (lpek,
2015; Levi, 2005). If Turkish were a pitch-accent language, and the bilinguals in our study transferred the acoustic correlates of Turkish word stress to Dutch, we would expect differences between the bilinguals and L1 speakers of Dutch. However, we did not find any differences in $\mathrm{f0}$ movements on stressed syllables nor any duration differences that were related to stress. This may indicate either that Turkish and Dutch have different acoustic correlates for word stress but that there is no evidence for transfer from Turkish to Dutch regarding these correlates, or that Turkish is a stress-accent language and marks stress identically to Dutch.

Below, we first describe the differences between the two groups of speakers for f0 movements, peak alignment, and duration, and then indicate whether the group differences can reflect an effect of Turkish on Dutch. Finally, we discuss gender differences and language dominance.

\subsubsection{FO movements}

First, the Turkish-Dutch bilinguals produced a higher minimum before the peak and a higher peak on the subject in the CONTR.S condition compared to the BROAD and CONTR.O conditions, while for the L1 speakers of Dutch there was no difference between contrastive focus and broad focus for these f0 movements on the subject. The slightly, though not significantly, higher peak height for the subject in broad focus than in contrastive focus for the Dutch L1 speakers is consistent with Hanssen et al. (2008), who concluded that (contrastive) narrow focus in nuclear position in Standard Dutch is not realized by a higher peak than broad focus. No studies have yet explored whether contrastive focus in Turkish is marked by higher peaks. If contrastive focus in Turkish is marked by a higher peak, the difference between the bilinguals and the Dutch L1 speakers could be explained by an effect of Turkish. A systematic comparison between the phonetic realization of broad and contrastive focus in Turkish is required to test this prediction.

Notably, we found the reverse for the peak on the object. The Dutch L1 speakers marked contrastive focus in sentence-final position with an increased peak compared to broad focus. The difference between the CONTR.O and BROAD conditions for the Turkish-Dutch bilinguals was more limited. In particular, for the Turkish-Dutch male bilinguals the difference between the CONTR. $\mathrm{O}$ and BROAD conditions did not reach significance. The difference between sentence-initial position (subject) and sentence-final position (object) may be relevant here for two reasons. First, there may be a difference between a nuclear accent on the subject, as is the case in CoNTR.S, when the following words are deaccented, and a nuclear accent on the object in CONTR.O. Even though the shape of these pitch accents is similar, given that they are all nuclear, there may be some phonetic differences due to the position in the sentence. For instance, the finality of the pitch accent in sentence-final position may lead to prosodic differences compared to non-final accents. Second, the difference between the groups concerning the peak on the object may be linked to the presence of declination. As described below, broad focus sentences spoken by the Dutch L1 speakers were characterized by a clear downward trend, whereas the bilinguals did not lower the final peak in this condition. Instead, they provided the object with a high peak. This resulted in a smaller difference between the BROAD and CONTR.O conditions for the Turkish-Dutch bilinguals than for the L1 speakers of Dutch. 
Gender also appeared to play a role in some of the fo differences found between the groups. First, the peak on the subject was higher in all conditions for female bilinguals than for female L1 speakers of Dutch, whereas male bilinguals realized lower peaks than male L1 speakers of Dutch in all conditions. Thus, the difference between male and female bilinguals regarding the difference in peak height was much larger than the difference between male and female L1 speakers of Dutch. Female bilinguals also employed higher peaks on the object in all conditions than female L1 speakers of Dutch. The difference between the two female groups was even larger here than for the peak on the subject. Concerning male speakers, the bilinguals realized somewhat lower peaks on the object than the L1 speakers of Dutch, although the difference between the groups was smaller than for the peak on the subject.

Second, male speakers of both groups generally employed a larger fall on the object than female speakers, particularly in broad focus. Third, all speakers, except for male bilinguals, marked contrastive focus on the object with a larger and steeper fall than in the other conditions; the male bilinguals employed an equally large fall on the object in broad and in contrastive focus. Possible explanations for the gender differences are discussed below.

Another difference between Turkish-Dutch bilinguals and L1 speakers of Dutch is that the L1 speakers of Dutch marked contrastive focus with a larger rise on both the subject and the object, whereas the bilinguals did not. Ipek (2011) demonstrated that words in neutral narrow focus were not marked by an expanded pitch range, but rather by duration and intensity differences. If contrastive focus in Turkish is also associated with an increased duration and intensity, the findings could be explained by transfer from Turkish.

The final difference concerning fo movements is peak range. Whereas the Dutch L1 speakers showed declination throughout the sentence, the Turkish-Dutch bilinguals did not. This difference was most clear in broad focus. The declination we found for the Dutch L1 speakers is in line with Chen (2007), who reported downstepped accents in her study. Moreover, according to Gussenhoven (2005a), final lowering in Dutch marks finality. The Turkish-Dutch bilinguals seemed to use two different strategies instead of declination, depending on gender. The female bilinguals used a higher peak on the object than the female Dutch L1 speakers, whereas the male bilinguals realized a lower peak on the subject than the male Dutch L1 speakers, leading both female and male bilinguals to continue at the same pitch level throughout the sentence.

Could these differences regarding declination between the bilinguals and Dutch L1 speakers point towards a Turkish influence? Two related features need to be considered here: peak range and the nuclear accent. First, for peak range, Ipek (2015) and Kamalı (2011) noted a limited peak range for Turkish broad focus in the prenuclear area, which is comparable to the lack of declination in Dutch that was observed for the bilinguals in our study. According to Kamalı (2011), declination in Turkish is reserved for the (post-) nuclear area, in which no accentuation is allowed. However, there is also a difference between what the bilinguals in our study did and what has been observed for Turkish (Ipek, 2015; Kamalı, 2011). This concerns the second feature: the nuclear accent. In Turkish, the nuclear accent following the prenuclear domain is marked by a compressed f0 range. Yet, the bilinguals in our study marked the nuclear accent in Dutch by a high peak. Unlike Turkish, Dutch makes no distinction between a prenuclear and (post-)nuclear area in SVO sentences. Kamalı (2011) argues that the fo lowering of the
Turkish nuclear accent is triggered by the declination in the postnuclear area. Sentence prominence is therefore not indicated on the nuclear accent, but by a high boundary tone at the right edge of the word preceding the nuclear accent (Ipek, 2015). The absence of a postnuclear area in Dutch might explain the equally high peaks in sentence-initial and sentence-final position in the bilinguals: There is no trigger to lower the pitch on the final word, and hence the relatively high peak on the nuclear accent marks prominence (instead of the high boundary tone in Turkish). This prominencemarking function of the nuclear accent might also explain why the bilinguals have not adopted the typical Dutch feature of final lowering to express finality of the sentence.

This finding can be related to Colantoni and Gurlekian (2004), who reported an influence of Italian regarding peak range in Argentinian Spanish. Instead of raising the final accent in other varieties of Spanish, Argentinian Spanish speakers lowered the final accent in the sentence compared to the initial accent, as in Italian. Possibly our findings are also related to Queen (2012), who found a phrase-final rise in the German of heritage speakers of Turkish in Germany. This rise indicated narrative salience, and was interpreted as a possible transfer from Turkish to German. The relatively high nuclear peak in broad focus sentences by the heritage speakers in our study also marks sentence prominence. However, the rise in German was characterized by a steep slope, whereas our bilinguals did not use a steeper rise on the object than the L1 speakers of Dutch. Further note that the different types of data (narratives in Queen, and answers to questions in our study) make a comparison between the German and Dutch prosody difficult.

\subsubsection{Peak alignment}

The Turkish-Dutch bilinguals and the Dutch L1 speakers also differed concerning peak alignment, in particular for the object. Although this peak fell within the stressed syllable in all conditions, which is typical of the $\mathrm{H} * \mathrm{~L}$ nuclear accent in Dutch, the bilinguals realized the peak earlier in the CONTR.O than in the BROAD condition, whereas the Dutch L1 speakers showed the opposite (earlier peak alignment for the BROAD than for the CONTR.O condition).

The difference in peak alignment in the present study might be attributed to a Turkish influence. Interestingly, peak alignment differences were found in various language contact situations (e.g., Atterer \& Ladd, 2004; Elordieta, 2003; Mennen, 2004), suggesting that peak alignment is sensitive to the effects of language contact. However, an analysis of peak alignment in Turkish is needed to test whether the observed differences are in fact due to an effect of Turkish. Hanssen et al. (2008) also found earlier peak alignment for contrastive focus than broad focus on the nuclear accent for native speakers of Dutch, similar to the Turkish-Dutch bilinguals, and unlike the Dutch L1 speakers in the present study. Differences in alignment might thus also be related to other factors, such as differences in other f0 movements and differences between read and (semi-)spontaneous speech (Face, 2003).

\subsubsection{Duration}

There was one durational difference between the bilinguals and the Dutch L1 speakers. The bilinguals showed longer objects relative to the subject than the Dutch L1 speakers in all conditions. Final lengthening is a characteristic of Dutch (Hofhuis et al., 1995), but that the bilinguals used even more final lengthening, regardless of focus condition, might reflect an 
aspect of Turkish prosody. An acoustic analysis of Turkish prosody is required to further explore this.

\subsubsection{Gender differences}

Remarkably, the measures we discussed so far were often modulated by gender differences in the groups. These gender differences may reflect two factors. First, some differences could be culturally motivated. In some languages, the differences in pitch between men and women are larger than in other languages (e.g., Gussenhoven, 2005a). For Dutch, the difference in pitch range between women and men appears to be small (e.g., Haan, 2002). In our study, the differences in pitch between the male and female bilinguals were large, whereas the male and female L1 speakers of Dutch were more similar, possibly revealing a cultural difference between the bilinguals and the L1 speakers of Dutch. We also found that both male bilinguals and male Dutch L1 speakers employed larger falls on the object than all female speakers. This could possibly also be related to cultural or social factors. Certain pitch movements, such as lowering, are associated with self-confidence and masculinity (Gussenhoven, 2005a). Male speakers might for this reason employ larger falls in sentence-final position than female speakers. More research is needed to investigate this issue.

Second, some differences between the male and female bilinguals might be explained by differences in prestige and attitudes towards the languages. The male bilinguals were the only speakers who did not mark contrastive focus on the object with a larger and steeper fall than the other focus conditions. If this prosodic feature is not used to mark contrastive focus in Turkish, as suggested by Ipek (2011), then the male bilinguals possibly showed an effect of Turkish in their Dutch prosody, while the female bilinguals adopted the Dutch feature. Given that Dutch is the prestige language in the Netherlands, this difference between male and female bilinguals is consistent with the leading role that women often take in language change and their tendency to use the prestige variants (Labov, 2001; Simonet, 2011). A study on attitudes towards different varieties of Dutch is needed to further explore this explanation.

\subsubsection{Language dominance}

Apart from gender, we did not find interactions between group of speakers (L1 speakers of Dutch and bilinguals) and other sociolinguistic variables, such as measures that might explain differences in language use. This might be attributed to the relatively homogeneous language use of the bilinguals. Information from the sociolinguistic questionnaire and the BNT scores revealed that for all bilinguals Dutch was the dominant language. Yet, the bilinguals differed from the Dutch L1 speakers regarding several prosodic features, which can possibly be explained by effects of Turkish.

As discussed in the introduction, many studies have shown unidirectional transfer from the dominant to the weaker language. Thus, language dominance is a more crucial factor for crosslinguistic effects than age of acquisition. Only a few studies suggest that even in early bilinguals the status of the $\mathrm{L} 1$ (the first that the child was exposed to) may play an important role, and, as such, an earlier established, yet weaker language may affect the dominant L2 in adult heritage speakers (Montrul, 2006; Queen, 2012; Van Meel et al., 2013, 2014). Our study provides new evidence that a dominant L2 acquired in early childhood can still show effects from the $L 1$, at least regarding prosody.

Another question related to language dominance is whether the cross-linguistic effects are bi-directional, as has been demonstrated for highly proficient Dutch L2 learners of Greek (Mennen, 2004). An analysis of Turkish as spoken by the same bilinguals might answer this question. Given that our bilinguals were dominant in Dutch, an effect of Dutch on Turkish seems to be likely as well. Thus, although our findings suggest that language dominance is not the only factor in cross-linguistic effects, we do not exclude the possibility of an effect of language dominance in the other direction: Language dominance may play a role in the possible effect of Dutch on Turkish.

\subsubsection{Explanations for $L 1$ prosodic transfer}

The three scenarios we discerned in the Introduction to account for L1 transfer in heritage speakers (direct transfer, early childhood transfer, and indirect transfer) are consistent with different findings in our study and thus are to some extent complementary. For example, the gender difference in pitch may be an instance of direct transfer, through co-activation of Turkish. This would be consistent with Muntendam et al. (2017), who found that Turkish heritage speakers co-activated Turkish during auditory processing in Dutch. It may also be an instance of indirect transfer, through accommodation via parents and peers (Romera \& Elordieta, 2013). However, other findings related to pitch, such as the lack of declination in broad focus, may be better explained by early childhood transfer. In this scenario, the heritage speakers transferred the prosodic phrasing characteristics of Turkish to Dutch in early childhood, when Turkish was their dominant language. In this way, heritage speakers introduced new prosodic characteristics to their Dutch. Future research could test these scenarios in more detail by comparing the Dutch prosody of adult second-generation Turkish heritage speakers to that of children and first-generation heritage speakers.

\subsection{Conclusion}

We have shown that the Dutch prosody of heritage speakers has different characteristics from that of Dutch L1 speakers who do not speak Turkish, and argue that these characteristics may be attributed to an effect from the heritage language on Dutch.

Our study contributes to work on prosody in general. To our knowledge, our study is the first that considers both sentenceinitial and sentence-final constituents in semi-spontaneous Dutch sentences in broad and contrastive focus, thereby adding to our knowledge of Dutch prosody. Moreover, while Peters et al. (2014) established prosodic differences across several varieties of West Germanic spoken in different areas, the present study adds a new variety to the list. The speakers of this variety have a different language background than considered before, because their L1 is Turkish. The bilinguals' prosody was most different from that of Dutch L1 speakers regarding peak range. While the $\mathrm{L} 1$ speakers of Dutch showed declination in broad focus, the bilinguals did not. This might be attributed to an effect from Turkish, which does not have declination in the prenuclear area (Ipek, 2015; Kamalı, 2011). The bilinguals also differed from the L1 speakers of Dutch regarding other aspects, such as fo movements and duration. Moreover, the difference in pitch between male and female speakers was larger for the bilinguals than for the $L 1$ speakers of Dutch, which may be linked to a cultural difference. The 
findings suggest that second-generation heritage speakers, who are highly proficient in the language of the society they live in, may still be sensitive to prosodic aspects from their heritage language. This interaction between the weaker L1 and dominant L2 adds valuable information to our understanding of the bilingual mind.

\section{Acknowledgements}

This project was funded by the Centre for Language Studies of the Radboud University. For valuable comments, we are grateful to the anonymous reviewers and to Carlos Gussenhoven. Furthermore, we thank all participants who dedicated their time to contribute to this study. We would also like to thank Geanne Welles for the design of the animated figure, Fedde Sappelli for the recordings, Marlies Swinkels for the translations of the BNT into Turkish, Ümmü Gülsüm Alkan for help with the analysis of the Turkish BNT, and Pascal de Water and Joop Kerkhoff for technical support. The pictures in the production task were adopted from http://www.clker.com and adjusted for the experiment.

\section{Appendix A. BNT scores and language proficiency ratings}

\section{Boston Naming Test (BNT; Kaplan et al., 2001)}

Table 12 shows the BNT scores of all participants. A paired ttest indicated that the bilinguals had significantly higher scores

Table 12

Means and standard deviations of Turkish and Dutch BNT scores for all female and male participants.

\begin{tabular}{llll}
\hline Gender & $\begin{array}{l}\text { Turkish BNT } \\
\text { (bilinguals) }\end{array}$ & $\begin{array}{l}\text { Dutch BNT } \\
\text { (bilinguals) }\end{array}$ & $\begin{array}{l}\text { Dutch BNT (control } \\
\text { group) }\end{array}$ \\
\hline Female & 84 & 103 & 133 \\
& 97 & 115 & 110 \\
& 69 & 91 & 138 \\
Male & 79 & 82 & 143 \\
& 53 & 65 & 142 \\
& 60 & 113 & 135 \\
Mean & 76 & 112 & 144 \\
SD & $\mathbf{7 2 . 8 8}$ & 119 & 149 \\
& $\mathbf{1 4 . 1}$ & $\mathbf{1 0 0}$ & $\mathbf{1 3 6 . 7 5}$ \\
\hline
\end{tabular}

Note: The maximum score was 162 .

Table 13

Self-reported language proficiency ratings (means and standard deviations) for all participants.

\begin{tabular}{llll}
\hline & $\begin{array}{l}\text { Mean (SD) } \\
\text { Turkish } \\
\text { (bilinguals) }\end{array}$ & $\begin{array}{l}\text { Mean (SD) Dutch } \\
\text { (bilinguals) }\end{array}$ & $\begin{array}{l}\text { Mean (SD) } \\
\text { Dutch (control } \\
\text { group) }\end{array}$ \\
\hline Speaking & $4.38(0.74)$ & $4.88(0.35)$ & $4.5(0.53)$ \\
Listening & $4.75(0.46)$ & $4.88(0.35)$ & $4.62(0.52)$ \\
Writing & $4.25(1.04)$ & $4.62(0.52)$ & $4.25(0.71)$ \\
Reading & $4(0.76)$ & $4.88(0.35)$ & $4.38(0.52)$ \\
Pronunciation & $4.25(0.71)$ & $4.75(0.46)$ & $4.5(0.53)$ \\
Mean & $\mathbf{4 . 3 3}$ & $\mathbf{4 . 8}$ & $\mathbf{4 . 4 5}$ \\
SD & $\mathbf{0 . 5 8}$ & $\mathbf{0 . 3 4}$ & $\mathbf{0 . 4 8}$ \\
\hline
\end{tabular}

Note: A score of 1 refers to 'not good at all', a score of 5 to 'very good'. on the Dutch than on the Turkish BNT $(t(7)=4.10, p<.01)$; mean (SD) for Dutch: 100 (19.04); mean (SD) for Turkish: 72.88 (14.1)). Moreover, an independent $t$-test showed that the female bilinguals scored significantly higher on the Turkish BNT than the male bilinguals $(t(5.81)=2.48, p<.05$; mean $(S D)$ females: 82.25 (11.64), versus 63.50 (9.68) for the males), whereas there was no significant gender difference for the Dutch BNT (mean (SD) for females: 97.75 (14.36); mean (SD) for males: 102.25 (25.02)). Furthermore, an independent t-test revealed significantly higher scores on the Dutch BNT (mean (SD): 136.75 (11.97)) for the Dutch L1 speakers than for the bilinguals ( $t$ $(11.88)=4.62, p<.001)$.

\section{Language proficiency ratings}

Table 13 shows the results of the language proficiency ratings. The proficiency scores of the bilinguals were higher for Dutch than for Turkish regarding all aspects (speaking, listening, reading, writing, and pronunciation), although paired t-tests only revealed a significant difference for reading $(t(7)=-$ 2.97, $p<.05)$, with higher scores for Dutch than for Turkish (mean (SD) for Dutch: 4.88 (0.35); mean (SD) for Turkish: 4 (0.76)). Furthermore, independent $t$-tests showed a significant difference between the bilinguals and Dutch L1 speakers for reading in Dutch $(t(12.37)=2.26, p<.05)$ : The bilinguals had significantly higher scores than the Dutch L1 speakers (mean (SD) for the bilinguals: 4.88 (0.35); mean (SD) for the Dutch L1 speakers: $4.38(0.52))$. While the Dutch $L 1$ speakers only rated their Dutch, the bilinguals rated their proficiency in two languages. The fact that the bilinguals compared their Dutch proficiency to Turkish might have caused the bilinguals' higher scores for Dutch on reading.

\section{Appendix B. Examples of the task}

See Figs. 14-16 here.

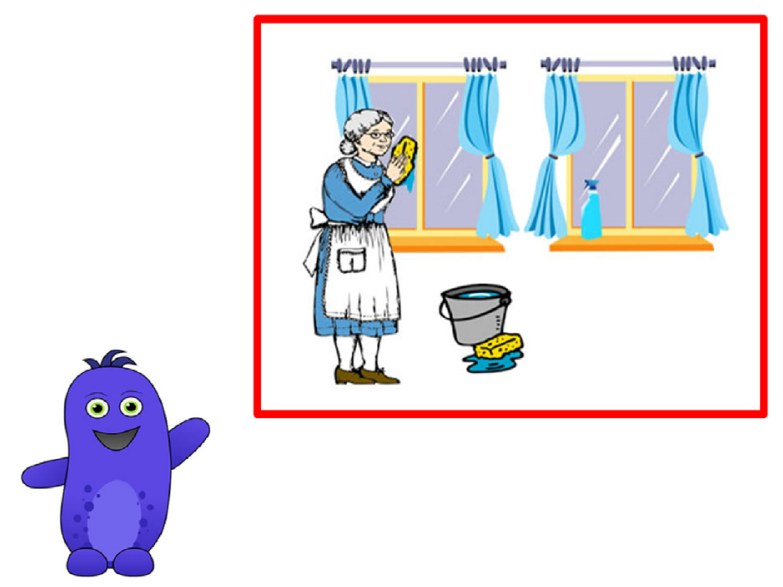

Fig. 14. Example context for BROAD. Q: Wat gebeurt er?, 'What is happening?' A: De oma wast de ramen, 'The grandmother is washing the windows.'. 


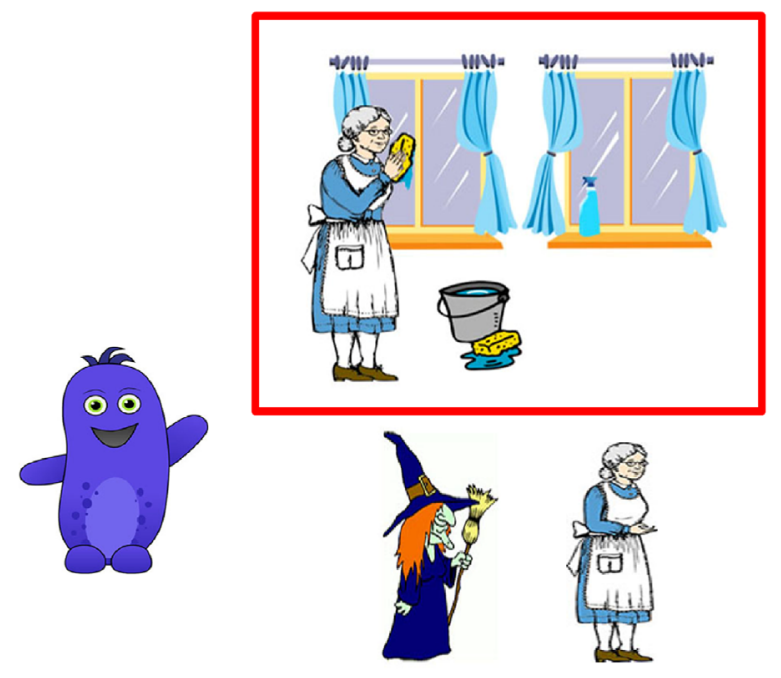

Fig. 15. Example context for Contr.S. Q: Wast de heks de ramen?, 'Is the witch washing the windows?' A: Nee, de oma wast de ramen, 'No, the grandmother is washing the windows.'.
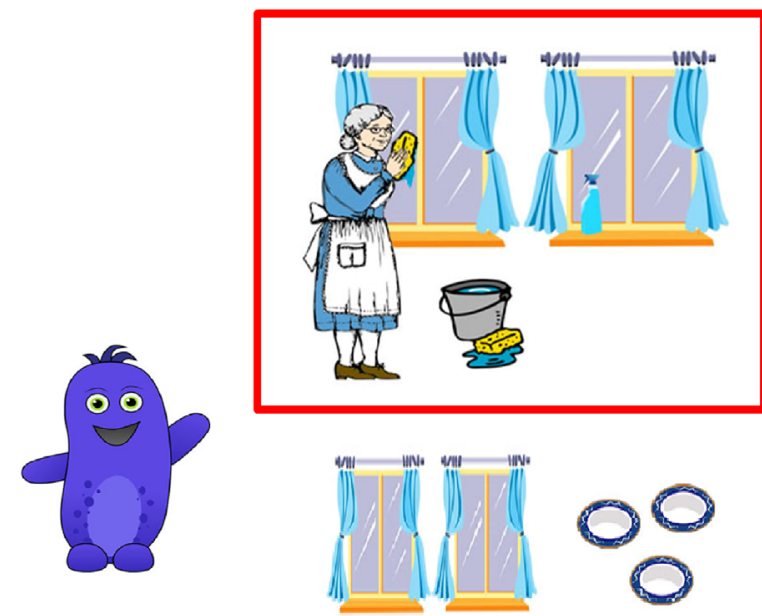

Fig. 16. Example context for ContR.O. Q: Wast de oma de borden?, 'Is the grandmother washing the plates?' A: Nee, de oma wast de ramen, 'No, the grandmother is washing the windows.'.

\section{Appendix C. N, means, and standard deviations for all measurements in Section 3}

See Tables 14-22 here.

\section{Table 14}

$N$, means and standard deviations in semitones for the minimum before the peak on the object.

\begin{tabular}{llllll}
\hline Measure & Condition & Gender & $N$ & Mean & SD \\
\hline Minimum before the peak & \multirow{2}{*}{ Broad } & F & 127 & 10.07 & 3.17 \\
& & M & 138 & 5.02 & 4.58 \\
& Contr.S & F & 143 & 8.52 & 3.83 \\
& & M & 150 & 1.51 & 2.86 \\
& Contr.O & F & 148 & 10.63 & 3.58 \\
& & M & 144 & 5.35 & 4.13 \\
\hline
\end{tabular}

Table 15

$N$, means and standard deviations in semitones for fo movements on the subject.

\begin{tabular}{llllll}
\hline Measure & Condition & Gender & $N$ & Mean & SD \\
\hline Slope rise & Broad & both & 255 & 2.27 & 1.56 \\
& Contr.S & both & 313 & 2.28 & 2.07 \\
& Contr.O & both & 283 & 1.87 & 1.80 \\
Minimum after the peak & Broad & F & 137 & 13.51 & 2.91 \\
& & M & 118 & 6.19 & 3.41 \\
& Contr.S & F & 161 & 10.60 & 3.45 \\
& & M & 151 & 3.34 & 4.27 \\
& Contr.O & F & 147 & 12.80 & 3.06 \\
Fall & & M & 137 & 4.91 & 3.41 \\
& Broad & both & 254 & 2.36 & 1.53 \\
Slope fall & Contr.S & both & 312 & 5.35 & 2.84 \\
& Contr.O & both & 284 & 1.88 & 1.46 \\
& Broad & both & 253 & 1.97 & 1.30 \\
& Contr.S & both & 312 & 2.65 & 1.32 \\
& Contr.O & both & 284 & 1.78 & 1.40 \\
\hline
\end{tabular}

Table 16

$N$, means and standard deviations in ms for peak location on the subject.

\begin{tabular}{lllll}
\hline Measure & Condition & $N$ & Mean & SD \\
\hline Peak location & Broad & 256 & 30.79 & 74.52 \\
& Contr.S & 313 & -31.47 & 62.46 \\
& Contr.O & 284 & 37.27 & 79.73 \\
\hline
\end{tabular}

Table 17

$N$, means and standard deviations in ms for duration measurements.

\begin{tabular}{lllll}
\hline Measure & Condition & $N$ & Mean & SD \\
\hline Duration of the stressed syllable & Broad & 259 & 211.58 & 61.56 \\
of the subject & Contr.S & 318 & 201.91 & 57.82 \\
& Contr.O & 291 & 197.55 & 53.46 \\
Total duration of the subject & Broad & 259 & 420.11 & 95.75 \\
& Contr.S & 318 & 418.82 & 85.17 \\
Relative duration of the subject & Contr.O & 291 & 377.17 & 82.94 \\
& Broad & 259 & 51.02 & 12.05 \\
& Contr.S & 291 & 49.09 & 13.37 \\
Duration of the stressed syllable & Contr.O & 318 & 53.25 & 12.46 \\
of the object & Broad & 266 & 214.65 & 53.41 \\
& Contr.S & 293 & 211.04 & 53.56 \\
Total duration of the object & Contr.O & 292 & 217.81 & 55.50 \\
& Broad & 266 & 470.02 & 101.24 \\
Relative duration difference & Contr.S & 293 & 456.32 & 94.11 \\
& Contr.O & 292 & 480.65 & 93.08 \\
& Broad & 213 & 4.05 & 14.31 \\
& Contr.S & 281 & 2.80 & 14.66 \\
& Contr.O & 261 & 7.74 & 14.45 \\
\hline
\end{tabular}


Table 18

$N$, means and standard deviations in semitones for fo movements on the subject.

\begin{tabular}{|c|c|c|c|c|c|c|}
\hline Measure & Condition & Group & Gender & $N$ & Mean & SD \\
\hline \multirow[t]{12}{*}{ Minimum before peak } & \multirow[t]{4}{*}{ Broad } & Turkish-Dutch & $\mathrm{F}$ & 66 & 12.11 & 2.60 \\
\hline & & Dutch control & $F$ & 72 & 10.90 & 2.47 \\
\hline & & Turkish-Dutch & $M$ & 60 & 3.26 & 2.84 \\
\hline & & Dutch control & M & 59 & 5.37 & 4.34 \\
\hline & \multirow[t]{4}{*}{ Contr.S } & Turkish-Dutch & $\mathrm{F}$ & 76 & 14.18 & 3.18 \\
\hline & & Dutch control & $\mathrm{F}$ & 86 & 10.87 & 2.19 \\
\hline & & Turkish-Dutch & M & 69 & 5.05 & 2.81 \\
\hline & & Dutch control & M & 82 & 6.29 & 4.34 \\
\hline & \multirow[t]{4}{*}{ Contr.O } & Turkish-Dutch & $\mathrm{F}$ & 67 & 12.25 & 2.87 \\
\hline & & Dutch control & $\mathrm{F}$ & 80 & 10.18 & 2.15 \\
\hline & & Turkish-Dutch & M & 62 & 3.09 & 2.78 \\
\hline & & Dutch control & M & 75 & 4.09 & 4.20 \\
\hline \multirow[t]{6}{*}{ Rise } & \multirow[t]{2}{*}{ Broad } & Turkish-Dutch & both & 125 & 3.58 & 2.61 \\
\hline & & Dutch control & both & 131 & 4.99 & 3.09 \\
\hline & \multirow[t]{2}{*}{ Contr.S } & Turkish-Dutch & both & 145 & 2.33 & 2.07 \\
\hline & & Dutch control & both & 168 & 4.06 & 3.42 \\
\hline & \multirow[t]{2}{*}{ Contr.O } & Turkish-Dutch & both & 129 & 2.93 & 2.25 \\
\hline & & Dutch control & both & 155 & 3.72 & 2.54 \\
\hline \multirow[t]{12}{*}{ Peak } & \multirow[t]{4}{*}{ Broad } & Turkish-Dutch & $\mathrm{F}$ & 65 & 16.01 & 3.18 \\
\hline & & Dutch control & $\mathrm{F}$ & 72 & 15.19 & 2.41 \\
\hline & & Turkish-Dutch & $M$ & 60 & 6.67 & 3.36 \\
\hline & & Dutch control & M & 59 & 11.22 & 5.07 \\
\hline & \multirow[t]{4}{*}{ Contr.S } & Turkish-Dutch & $F$ & 76 & 16.42 & 3.35 \\
\hline & & Dutch control & $F$ & 86 & 14.42 & 2.52 \\
\hline & & Turkish-Dutch & $M$ & 69 & 7.48 & 2.72 \\
\hline & & Dutch control & M & 82 & 10.88 & 5.77 \\
\hline & \multirow[t]{4}{*}{ Contr.O } & Turkish-Dutch & $F$ & 67 & 15.27 & 3.43 \\
\hline & & Dutch control & $\mathrm{F}$ & 80 & 13.80 & 2.58 \\
\hline & & Turkish-Dutch & M & 62 & 5.92 & 3.34 \\
\hline & & Dutch control & $M$ & 75 & 7.91 & 3.59 \\
\hline
\end{tabular}

Table 19

$\mathrm{N}$, means and standard deviations in semitones for f0 movements on the object.

\begin{tabular}{|c|c|c|c|c|c|c|}
\hline Measure & Condition & Group & Gender & $N$ & Mean & SD \\
\hline \multirow[t]{6}{*}{ Rise } & \multirow[t]{2}{*}{ Broad } & Turkish-Dutch & both & 118 & 1.27 & 1.49 \\
\hline & & Dutch control & both & 145 & 1.22 & 2.12 \\
\hline & \multirow[t]{2}{*}{ Contr.S } & Turkish-Dutch & both & 135 & 0.74 & 0.97 \\
\hline & & Dutch control & both & 157 & 0.69 & 0.90 \\
\hline & \multirow[t]{2}{*}{ Contr.O } & Turkish-Dutch & both & 131 & 1.37 & 1.79 \\
\hline & & Dutch control & both & 160 & 2.18 & 2.86 \\
\hline \multirow[t]{12}{*}{ Peak } & \multirow[t]{4}{*}{ Broad } & Turkish-Dutch & $\mathrm{F}$ & 56 & 13.10 & 3.04 \\
\hline & & Dutch control & $\mathrm{F}$ & 71 & 9.10 & 2.43 \\
\hline & & Turkish-Dutch & M & 62 & 5.49 & 2.85 \\
\hline & & Dutch control & $M$ & 74 & 7.78 & 6.58 \\
\hline & \multirow[t]{4}{*}{ Contr.S } & Turkish-Dutch & $\mathrm{F}$ & 68 & 11.09 & 3.21 \\
\hline & & Dutch control & $\mathrm{F}$ & 75 & 7.54 & 3.39 \\
\hline & & Turkish-Dutch & M & 67 & 1.58 & 1.93 \\
\hline & & Dutch control & $M$ & 82 & 2.81 & 3.29 \\
\hline & \multirow[t]{4}{*}{ Contr.O } & Turkish-Dutch & $\mathrm{F}$ & 67 & 14.23 & 3.19 \\
\hline & & Dutch control & $\mathrm{F}$ & 80 & 9.57 & 2.25 \\
\hline & & Turkish-Dutch & $M$ & 64 & 5.76 & 2.57 \\
\hline & & Dutch control & $M$ & 80 & 9.80 & 6.12 \\
\hline \multirow[t]{12}{*}{ Fall } & \multirow[t]{4}{*}{ Broad } & Turkish-Dutch & $\mathrm{F}$ & 56 & 4.28 & 1.87 \\
\hline & & Dutch control & $\mathrm{F}$ & 71 & 3.89 & 3.11 \\
\hline & & Turkish-Dutch & $M$ & 61 & 7.21 & 3.67 \\
\hline & & Dutch control & M & 73 & 7.79 & 4.33 \\
\hline & \multirow[t]{4}{*}{ Contr.S } & Turkish-Dutch & $\mathrm{F}$ & 68 & 2.39 & 1.54 \\
\hline & & Dutch control & $\mathrm{F}$ & 75 & 2.63 & 2.26 \\
\hline & & Turkish-Dutch & M & 67 & 3.03 & 1.83 \\
\hline & & Dutch control & M & 82 & 2.77 & 1.32 \\
\hline & \multirow[t]{4}{*}{ Contr.O } & Turkish-Dutch & $\mathrm{F}$ & 67 & 5.71 & 2.01 \\
\hline & & Dutch control & $\mathrm{F}$ & 79 & 4.22 & 3.27 \\
\hline & & Turkish-Dutch & $M$ & 64 & 6.98 & 2.96 \\
\hline & & Dutch control & M & 80 & 9.56 & 4.24 \\
\hline \multirow[t]{12}{*}{ Fall slope } & \multirow[t]{4}{*}{ Broad } & Turkish-Dutch & $\mathrm{F}$ & 56 & 1.83 & 0.89 \\
\hline & & Dutch control & $\mathrm{F}$ & 71 & 1.98 & 1.19 \\
\hline & & Turkish-Dutch & M & 61 & 2.94 & 1.39 \\
\hline & & Dutch control & M & 73 & 3.22 & 1.79 \\
\hline & \multirow[t]{4}{*}{ Contr.S } & Turkish-Dutch & $\mathrm{F}$ & 68 & 1.42 & 1.31 \\
\hline & & Dutch control & $\mathrm{F}$ & 75 & 1.84 & 1.30 \\
\hline & & Turkish-Dutch & $M$ & 67 & 1.43 & 0.96 \\
\hline & & Dutch control & M & 82 & 1.30 & 0.65 \\
\hline & \multirow[t]{4}{*}{ Contr.O } & Turkish-Dutch & $\mathrm{F}$ & 67 & 2.23 & 0.77 \\
\hline & & Dutch control & $\mathrm{F}$ & 79 & 2.26 & 1.33 \\
\hline & & Turkish-Dutch & M & 64 & 2.95 & 1.27 \\
\hline & & Dutch control & M & 80 & 4.07 & 1.85 \\
\hline
\end{tabular}


Table 20

$N$, means and standard deviations in semitones for peak range.

\begin{tabular}{lllllll}
\hline Measure & Condition & Group & Gender & $N$ & Mean & SD \\
\hline \multirow{2}{*}{ Peak range } & \multirow{2}{*}{ Broad } & Turkish-Dutch & F & 46 & 2.62 & 2.00 \\
& & Dutch control & F & 62 & 6.36 & 1.98 \\
& Turkish-Dutch & M & 53 & 1.11 & 3.13 \\
& Dutch control & M & 63 & 2.55 & 2.89 \\
& \multirow{4}{*}{ Contr.S } & Turkish-Dutch & F & 64 & 5.16 & 2.84 \\
& & Dutch control & F & 72 & 7.33 & 3.59 \\
& Turkish-Dutch & M & 63 & 6.09 & 2.54 \\
& Dutch control & M & 82 & 8.07 & 3.02 \\
& Contr.O & Turkish-Dutch & F & 55 & 1.10 & 2.19 \\
& & Dutch control & F & 72 & 4.56 & 2.35 \\
& Turkish-Dutch & M & 58 & 0.55 & 3.32 \\
& Dutch control & M & 73 & -2.24 & 3.50 \\
\hline
\end{tabular}

Table 21

$N$, means and standard deviations in ms for peak location on the object.

\begin{tabular}{llllll}
\hline Measure & Condition & Group & $N$ & Mean & SD \\
\hline Peak location & \multirow{2}{*}{ Broad } & Turkish-Dutch & 118 & -108.81 & 68.55 \\
& & Dutch control & 145 & -124.60 & 60.85 \\
& Contr.S & Turkish-Dutch & 135 & -117.76 & 64.47 \\
& & Dutch control & 157 & -115.37 & 59.00 \\
& Contr.O & Turkish-Dutch & 131 & -114.98 & 65.51 \\
& & Dutch control & 160 & -107.93 & 64.00 \\
\hline
\end{tabular}

Table 22

$\mathrm{N}$, means and standard deviations in $\mathrm{ms}$ for total duration difference.

\begin{tabular}{llllll}
\hline Measure & Condition & Group & $N$ & Mean & SD \\
\hline Total duration & \multirow{2}{*}{ Broad } & Turkish-Dutch & 100 & -66.84 & 154.88 \\
subject - total & & Dutch control & 113 & -46.81 & 110.83 \\
duration object & \multirow{2}{*}{ Contr.S } & Turkish-Dutch & 129 & -61.49 & 118.98 \\
& & Dutch control & 152 & -23.38 & 105.00 \\
& \multirow{2}{*}{ Contr.O } & Turkish-Dutch & 116 & -99.66 & 127.41 \\
& & Dutch control & 145 & -101.36 & 103.38 \\
\hline
\end{tabular}

\section{References}

Abutalebi, J., \& Green, D. (2007). Bilingual language production: The neurocognition of language representation and control. Journal of Neurolinguistics, 20, 242-275.

Amengual, M. (2012). Interlingual influence in bilingual speech: Cognate status effect in a continuum of bilingualism. Bilingualism: Language and Cognition, 15, 517-530.

Argyri, E., \& Sorace, A. (2007). Crosslinguistic influence and language dominance in older bilingual children. Bilingualism: Language and Cognition, 10, 79-99.

Atterer, M., \& Ladd, D. R. (2004). On the phonetics and phonology of "segmental anchoring" of F0: Evidence from German. Journal of Phonetics, 32, 177-197.

Beckman, M. E. (1986). Stress and non-stress accent, Vol. 7. Berlin, Germany: Walter de Gruyter.

Benmamoun, E., Montrul, S., \& Polinsky, M. (2013). Heritage languages and their speakers: Opportunities and challenges for linguistics. Theoretical Linguistics, 39, 129-181.

Blaauw, E. (1994). The contribution of prosodic boundary markers to the perceptual difference between read and spontaneous speech. Speech Communication, 14, 359-375.

Blom, E., \& Baayen, H. R. (2013). The impact of verb form, sentence position, home language, and second language proficiency on subject-verb agreement in child second language Dutch. Applied Psycholinguistics, 34, 777-811.

Blumenfeld, H. K., \& Marian, V. (2007). Constraints on parallel activation in bilingual spoken language processing: Examining proficiency and lexical status using eyetracking. Language and Cognitive Processes, 22, 633-660.

Boersma, P., \& Weenink, D. (2010). Praat: Doing phonetics by computer. Version 5.3.80 Retrieved from $\langle$ http://www.praat.org/

Bolonyai, A. (2007). In)vulnerable agreement in incomplete bilingual L1 learners. International Journal of Bilingualism, 11, 3-23.

Bouma, G. J. (2008). Starting a sentence in Dutch. A corpus study of subject- and objectfronting Ph.D. dissertation. University of Groningen.

Bullock, B. (2009). Prosody in contact in French: A case study from a heritage variety in the USA. International Journal of Bilingualism, 13, 165-194.
Chang, C. B., Haynes, E. F., Yao, Y., \& Rhodes, R. (2008). The phonetic space of phonological categories in heritage speakers of Mandarin. UC Berkeley. Retrieved from: 〈http://escholarship.org/uc/item/8zc3m9vr 〉.

Chang, C. B., Haynes, E. F., Yao, Y., \& Rhodes, R. (2009). A tale of five fricatives: Consonantal contrast in heritage speakers of Mandarin. UC Berkeley. Retrieved from: 〈http://escholarship.org/uc/item/5t2092k9〉.

Chen, A. (2007). Intonational realisation of topic and focus by Dutch-acquiring 4- to 5-yearolds. In J. Trouvain \& W. J. Barry (Eds.), Proceedings of International Congress of Phonetic Sciences XVI (pp. 1553-1556). Saarbrücken, Germany.

Chen, A. (2009). The phonetics of sentence-initial topic and focus in adult and child Dutch. In M. Vigário, S. Frota, \& M. J. Freitas (Eds.), Phonetics and phonology: Interactions and interrelations (pp. 91-106). Amsterdam: John Benjamins.

Chen, A. (2011). Tuning information packaging: Intonational realization of topic and focus in child Dutch. Journal of Child Language, 38, 1055-1083

Christophe, A. Nespor, M., Guasti, M. T. \& Van Ooyen, B. (2003). Prosodic structure and syntactic acquisition: the case of the head-direction parameter. Developmental Science, 6, 211-220.

Colantoni, L., \& Gurlekian, J. (2004). Convergence and intonation: Historical evidence from Buenos Aires Spanish. Bilingualism: Language and Cognition, 7, 107-119.

Costa, A. (2005). Lexical access in bilingual production. In J. Kroll, \& A. De Groot (Eds.), Handbook of bilingualism: Psycholinguistic approaches (pp. 308-325). New York: Oxford University Press.

Daller, M. H., Treffers-Daller, J., \& Furman, R. (2011). Transfer of conceptualization patterns in bilinguals: The construal of motion events in Turkish and German. Bilingualism: Language and Cognition, 14, 95-119.

Dijkstra, T. (2005). Bilingual visual word recognition and lexical access. In J. Kroll, \& A. De Groot (Eds.), Handbook of bilingualism: Psycholinguistic approaches (pp. 179-201). New York: Oxford University Press.

Dijkstra, T., Grainger, J., \& Van Heuven, W. J. B. (1999). Recognition of cognates and interlingual homographs: The neglected role of Phonology. Journal of Memory and Language, 41496-518.

Doğruöz, S. A., \& Backus, A. (2007). Postverbal elements in immigrant Turkish: Evidence of change?. International Journal of Bilingualism, 11, 185-220.

Doğruöz, S. A., \& Backus, A. (2009). Innovative constructions in Dutch Turkish: An assessment of ongoing contact-induced change. Bilingualism: Language and Cognition, 12, 41-63.

Elordieta, G. (2003). The Spanish intonation of speakers of a Basque pitch-accent dialect. Catalan Journal of Linguistics, 2, 67-95.

Elordieta, G., \& Calleja, N. (2005). Microvariation in accentual alignment in Basque Spanish. Language and Speech, 48, 397-439.

Extra, G., Yağmur, K., \& van der Avoird, T. (2004). Methodological considerations. In G. Extra, \& K. Yağmur (Eds.), Urban multilingualism in Europe: Immigrant minority languages at home and school (pp. 109-132). Clevedon: Multilingual Matters.

Face, T. (2003). Intonation in Spanish declaratives: Differences between lab speech and spontaneous speech. Catalan Journal of Linguistics, 2, 115-131.

Gerken, L., Jusczyk, P. W., \& Mandel, D. R. (1994). When prosody fails to cue syntactic structure: 9-month-olds' sensitivity to phonological versus syntactic phrases. Cognition, 51, 237-265.

Gout, A., Christophe, A., \& Morgan, J. L. (2004). Phonological phrase boundaries constrain lexical access II. Infant data. Journal of Memory and Language, 51, 548-567.

Güneș, G. (2013). On the role of prosodic constituency in Turkish. In U. Özge (Ed.), The Proceedings of workshop on Altaic formal linguistics, Vol. 8 (pp. 115-128). Cambridge, MA: MITWPL.

Gussenhoven, C. (2005a). The phonology of tone and intonation. Cambridge, UK: Cambridge University Press.

Gussenhoven, C. (2005b). Transcription of Dutch intonation. In S. Jun (Ed.), Prosodic typology and transcription: A unified approach. Oxford, UK: Oxford University Press.

Gussenhoven, C. (2007). Types of focus in English. In C. Lee, M. Gordon, \& D. Büring (Eds.), Topic and focus: Cross-linguistic perspectives on meaning and intonation (pp. 83-100). Heidelberg/New York/London: Springer.

Gut, U. B. (2005). Nigerian English prosody. English World-wide, 26, 153-177.

Haan, J. (2002). Speaking of questions. An exploration of Dutch question intonation Ph.D. dissertation. Utrecht University.

Hanssen, J., Peters, J., \& Gussenhoven, C. (2008). Prosodic effects of focus in Dutch declaratives. In P. A. Barbosa, S. Madureira and C. Reis (Eds.), Proceedings of the 4th international conference on speech prosody, 6-9 May (pp. 609-612). Campinas.

Hartsuiker, R. J., Pickering, M. J., \& Veltkamp, E. (2004). Is syntax separate or shared between languages? Cross-linguistic syntactic priming in Spanish-English bilinguals. Psychological Science, 15, 409-414

Hatzidaki, A., Branigan, H. P., \& Pickering, M. J. (2011). Co-activation of syntax in bilingual language production. Cognitive Psychology, 62, 123-150.

Hernandez, A., Li, P., \& MacWhinney, B. (2005). The emergence of competing modules in bilingualism. Trends in Cognitive Sciences, 9, 220-225.

Hofhuis, E. M. F. J., Gussenhoven, C., \& Rietveld, T. (1995). Final lengthening at prosodic boundaries in Dutch. In E. Elenius, \& P. Branderud, (Eds.), Proceedings of the XIIIth international congress of phonetic sciences, Vol. 1 (pp. 154-157). Stockholm.

Hohenstein, J., Eisenberg, A., \& Naigles, L. (2006). Is he floating across or crossing afloat? Cross-influence of L1 and L2 in Spanish-English bilingual adults. Bilingualism: Language and Cognition, 9249-261.

Inkelas, S. (1999). The exceptional stress-attracting suffixes in Turkish: Representations versus the grammar. In R. Kager, H. van der Hulst, \& W. Zonneveld (Eds.), The prosody-morphology interface (pp. 134-187). Cambridge, UK: Cambridge University Press.

Inkelas, S., \& Orgun, C. O. (2003). Turkish stress: A review. Phonology, 20, 139-161. 
Ipek, C. (2011). Phonetic realization of focus with no on-focus pitch range expansion in Turkish. In Proceedings of the 17th International congress of phonetic sciences ( $\mathrm{pp}$. 140-143). Hong Kong.

Ipek, C. (2015). The phonology and phonetics of Turkish intonation Ph.D. dissertation. University of Southern California.

Ipek, C., \& Jun, S. (2013). Towards a model of intonational phonology of Turkish: Neutral intonation. Proceedings of Meetings on Acoustics, Vol. 19, 1-9, http://dx.doi.org/ 10.1121/1.4799755

İssever, S. (2003). Information structure in Turkish: The word order-prosody interface. Lingua, 113, 1025-1053.

Jackendoff, R. (1972). Semantic interpretation in Generative Grammar. Cambridge, MA: MIT Press.

Kabak, B., \& Vogel, I. (2001). The phonological word and stress assignment in Turkish. Phonology, 18, 315-360.

Kamalı, B. (2011). Topics at the pf interface of Turkish Ph.D. dissertation. Harvard University.

Kaplan, E., Goodglass, H., Weintraub, S., Segal, O., \& van Loon-Vervoorn, A. (2001). Boston naming test. Pro-ed; Austin, TX.

Krahmer, E., \& Swerts, M. (2001). On the alleged existence of contrastive accents. Speech Communication, 34, 391-405.

Kuznetsova, A., Brockhoff, P.B. and Bojesen Christensen, R.H. (2014). ImerTest: Tests for random and fixed effects for linear mixed effect models (Imer objects of Ime4 package). $\mathrm{R}$ package version 2.0-11. 〈http://CRAN.R-project.org/package $=\mid$ merTest .

Labov, W. (2001). Principles of linguistic change: Social factors, vol. 2. London: Blackwell.

Ladd, D. R. (2008). Intonational phonology ((2nd edition). Cambridge: Cambridge University Press.

Ladd, D. R., Mennen, I., \& Schepman, A. (2000). Phonological conditioning of peak alignment in rising pitch accents in Dutch. The Journal of the Acoustical Society of America, 107, 2685-2696.

Levi, S. V. (2005). Acoustic correlates of lexical accent in Turkish. Journal of the International Phonetic Association, 35, 73-97.

McAllister, R., Flege, J. E., \& Piske, T. (2002). The influence of L1 on the acquisition of Swedish quantity by native speakers of Spanish, English and Estonian. Journal of Phonetics, 30, 229-258

McCarthy, K. M., Evans, B. G., \& Mahon, M. (2013). Acquiring a second language in an immigrant community: The production of Sylheti and English stops and vowels by London-Bengali speakers. Journal of Phonetics, 41, 344-358.

McGory, J. T. (1997). Acquisition of intonational prominence in English by Seoul Korean and Mandarin Chinese speakers Ph.D. dissertation. The Ohio State University.

Mennen, I. (2004). Bi-directional interference in the intonation of Dutch speakers of Greek. Journal of Phonetics, 32, 543-563.

Montrul, S. (2004a). Subject and object expression in Spanish heritage speakers: A case of morphosyntactic convergence. Bilingualism: Language and Cognition, 7, 125-142.

Montrul, S. (2004b). Convergent outcomes in second language acquisition and first language loss. In M. Schmid, B. Köpke, M. Keijzer, \& L. Weilemar (Eds.), First language Attrition: Interdisciplinary perspectives on methodological issues (pp. 259280). Amsterdam: John Benjamins.

Montrul, S. (2006). On the bilingual competence of Spanish heritage speakers: Syntax, lexical-semantics and processing. International Journal of Bilingualism, 10, 37-69.

Montrul, S. A. (2008). Incomplete acquisition in bilingualism: Re-examining the age factor Vol. 39. Amsterdam: John Benjamins.

Montrul, S., \& Ionin, T. (2010). Transfer effects in the interpretation of definite articles by Spanish heritage speakers. Bilingualism: Language and Cognition, 13, 449-473.

Montrul, S., \& Ionin, T. (2012). Dominant language transfer in Spanish heritage speakers and second language learners in the interpretation of definite articles. The Modern Language Journal, 96, 70-94.

Muntendam, A. (2009). Linguistic transfer in Andean Spanish: syntax or pragmatics? Ph. D. dissertation. University of Illinois at Urbana-Champaign.

Muntendam, A. (2013). On the nature of cross-linguistic influence: A case study of Andean Spanish. Bilingualism: Language and Cognition, 16, 111-131.
Muntendam, A. (2015). Discourse deixis in Southern Quechua: A case study on topic and focus. In M. Manley, \& A. G. Muntendam (Eds.), Quechua expressions of stance and deixis. Brill Studies in the Indigenous Languages of the Americas.

Muntendam, A., Van Rijswijk, R., \& Dijkstra, T. (2017). The role of stress position in bilingual auditory word recognition: Cognate processing in Turkish and Dutch (in preparation).

Nooteboom, S. G. (1972). Production and perception of vowel duration. A study of durational properties of vowels in Dutch Ph.D dissertation. Utrecht University.

Özge, U., \& Bozsahin, C. (2010). Intonation in the grammar of Turkish. Lingua, 120, $132-175$.

Peters, J., Hanssen, J., \& Gussenhoven, C. (2014). The phonetic realization of focus in West Frisian, Low Saxon, High German, and three varieties of Dutch. Journal of Phonetics, 46, 185-209.

Polinsky, M. (2006). Incomplete acquisition: American Russian. Journal of Slavic Linguistics, 14, 191-262.

Queen, R. (2012). Turkish-German bilinguals and their intonation: Triangulating evidence about contact-induced language change. Language, 88, 791-816.

R Core Team (2014). R: A language and environment for statistical computing. Vienna Austria: R Foundation for Statistical Computing URL〈http://www.R-project.org/〉.

Romera, M., \& Elordieta, G. (2013). Prosodic accommodation in language contact: Spanish intonation in Majorca. International Journal of the Sociology of Language $127-151$.

Selinker, L., \& Gass, S. M. (Eds.). (1992). Language transfer in language learning. Amsterdam: John Benjamins.

Serratrice, L. (2007). Referential cohesion in the narratives of bilingual English-Italian children and monolingual peers. Journal of Pragmatics, 39, 1058-1087.

Simonet, M. (2008). Language contact in Majorca. An experimental sociophonetic approach Ph.D. dissertation. University of Illinois at Urbana-Champaign.

Simonet, M. (2011). Intonational convergence in language contact: Utterance-final FO contours in Catalan-Spanish early bilinguals. Journal of the International Phonetic Association, 41, 157-184.

Simpson, A. P. (2009). Phonetic differences between male and female speech. Language and Linguistics Compass, 3, 621-640.

Sluijter, A. M. C. \& van Heuven, V. J. J. P. (1995). Effects of focus distribution, pitch accent and lexical stress on the temporal organization of syllables in Dutch Phonetica, 52, 71-89.

Sluijter, A. M. \& Van Heuven, V. J. (1996). Spectral balance as an acoustic correlate of linguistic stress. The Journal of the Acoustical Society of America, 100, 2471-2485.

Soderstrom, M., Seidl, A., Nelson, D. G. K., \& Jusczyk, P. W. (2003). The prosodic bootstrapping of phrases: Evidence from prelinguistic infants. Journal of Memory and Language, 49, 249-267.

Statistics Netherlands (2014). Jaarrapport Integratie [Annual report on integration] Retrieved from Centraal Bureau voor de Statistiek, The Hague: 〈http://www.cbs.nl/ NR/rdonlyres/E6878ED8-0347-4ED0-8A8D-360AB79022B2/0/jaarrapportintegra tie2014pub.pdf).

Turco, G., Braun, B., \& Dimroth, C. (2014). When contrasting polarity, the Dutch use particles, Germans intonation. Journal of Pragmatics, 62, 94-106.

Vallduví, E., \& Engdahl, E. (1996). The linguistic realisation of information packaging Linguistics, 34, 459-519.

Van Donselaar, W., Koster, M., \& Cutler, A. (2005). Exploring the role of lexical stress in lexical recognition. The Quarterly Journal of Experimental Psychology, 58A, 251-273.

Van Heuven, V. J. J. P. (2014). Stress and segment duration in Dutch. In R. Kager, J. Grijzenhout, \& K. Sebregts (Eds.), Where the principles fail. A festschrift for Wim Zonneveld on the occasion of his 64th birthday (pp. 217-228). Utrecht: Utrecht Institute of Linguistics OTS.

Van Meel, L., Hinskens, F., \& Van Hout, R. (2013). Ethnolectal variation in the realization of /z/ by Dutch youngsters. Zeitschrift für Dialektologie und Linguistik, 80, 297-325.

Van Meel, L., Hinskens, F., \& Van Hout, R. (2014). Variation in the realization of $/ \varepsilon i /$ by Dutch youngsters: from local urban dialects to emerging ethnolects?. Dialectologia et Geolinguistica, 22, 46-74, http://dx.doi.org/10.1515/dialect-2014-0004.

Verhoeven, L. (2007). Early bilingualism, language transfer, and phonological awareness. Applied Psycholinguistics, 28, 425-439. 